\title{
The Measurement of Aircraft Performance and Stability and Control After Flight Through Natural Icing Conditions
}

Richard J. Ranaudo, Kevin L. Mikkelsen, Robert C. McKnight, Robert F. Ide, and Andrew L. Reehorst Lewis Research Center

Cleveland, Ohio

and

Jerry L. Jordan, William C. Schinstock, and Stewart J. Platz

Kohlman Systems Research, Inc.

Lawrence, Kansas

Loblabi bou

JUL 1 198ติ

LANGLEY RESEARCH CENTER

LIBRARY, NASA

HAMPTON, VIRGINIA'

Prepared for the

3rd Flight Testing Conference

cosponsored by the AIAA, AHS, CASI, DGLR,

IES, ISA, ITEA, SETP, and SFTE

Las Vegas, Nevada, April 2-4, 1986 


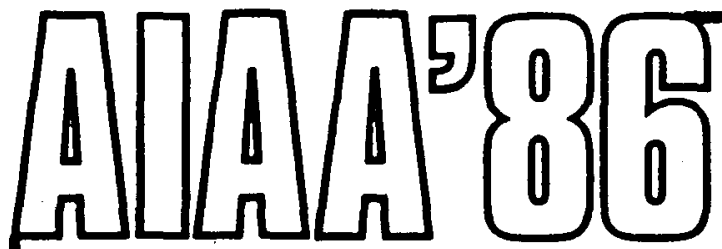

AIAA-86-9758

The Measurement of Aircraft Performance and Stability and Control After Flight Through Natural Icing Conditions Richard J. Ranaudo, Kevin L. Mikkelsen, Robert C. McKnight, Robert F. Ide, and Andrew L. Reehorst, Lewis Research Center, Cleveland, $\mathrm{OH}$; and Jerry L. Jordan, William C. Schinstock, and Stewart J. Platz, Kohlman Systems Research, Inc., Lawrence, KA

\section{AIAA/AHS/CASI/DGLR/IES/ISA/ITEA/SETPI SFTE 3rd Flight Testing Conference April 2-4, 1986/Las Vegas, Nevada}


THE MEASUREMENT OF AIRCRAFT PERFORMANCE AND STABILITY AND

CONTROL AFTER FLIGHT THROUGH NATURAL ICING CONOITIONS

Richard J. Ranaudo, Kevin L. Mikkelsen, Robert C. Mcknight, Robert F. Ide, and Andrew L. Reehorst

National Aeronautics and Space Administration

Lewis Research Center

Cleveland, Ohio 44135

and

Jerry L. Jordan, William C. Schinstock, and Stewart J. Platz Kohlman Systems Research, Inc.

Lawrence, Kansas 66044

\section{Abstract}

The effects of airframe icing on the performance and stability and control of a twin-engine commuter-class aircraft were measured by the NASA Lewis Research Center. This work consisted of clear air tests with artificial ice shapes attached to the horizontal tail, and natural icing flight tests in measured icing clouds. The clear air tests employed static longitudinal flight test methods to determine degradation in stability margins for four simulated ice shapes. The natural icing flight tests employed dynamic flight maneuvers and a compatible data acquisition system, which was provided under contract to NASA by Kohlman Systems Research Incorporated. This system used a performance modeling method and modified maximum likelihood estimation (MMLE) technique to determine aircraft performance degradation and stability and control. Flight test results with artificial ice shapes showed that longitudinal, stick-fixed, static margins are reduced on the order of 5 percent with flaps up. Natural icing tests with the KSR system corroborated these results and showed degradation in the elevator control derivatives on the order of 8 to 16 percent depending on wing flap configuration. Performance analyses showed the individual contributions of major airframe components to the overall degradation in lift and drag.

Performance modeling methods and MMLE techniques are viable flight test methods for determining the effects of natural ice on aircraft performance and stability and control. These techniques have an advantage over static methods because they provide for a rapid acquisition of flight test data in an environment where test time is constrained by the rate that ice shapes sublimate, melt, or erode. Measurements of stability and control with MMLE are limited to those portions of the flight envelope where aircraft response remains essentially buffet-free.

\section{Symbols and Definitions}

$\mathrm{C}_{\mathrm{D}}$ aircraft drag coefficient

$\mathrm{C}_{\mathrm{L}}$ $\left(C_{L_{q}}+C_{L_{\dot{a}}}\right) M M L E$ derived state coefficient, per rad $C_{L_{\alpha}}$ aircraft lift curve slope, per deg
$C_{L_{e}}$

$C_{m}$

$c_{m}$

$\left(c_{m_{q}}+c_{m_{\dot{\alpha}}}\right)$ change in aircraft lift coefficient with elevator deflection (elevator effectiveness) per deg

aircraft pitching moment, untrimmed

aircraft static pitching moment parameter, per deg

$c_{m} \quad$ change in aircraft pitching moment with elevator deflection (elevator power) per deg

$\mathrm{C}_{\mathrm{T}} \quad$ thrust coefficient

$\mathrm{C}_{\mathrm{A}}$

aircraft normal force coefficient obtained by $g \times W / q \times S$

$\mathrm{Fe} / \mathrm{q} \quad$ elevator control force normalized by dynamic pressure

FSSP forward scattering spectrometer probe

g

KCAS calibrated airspeed, knots

LWC liquid water content in cloud, $\mathrm{gm} / \mathrm{m}^{3}$

M Mach number

MAC mean aerodynamic chord of the wing, $f t$

MMLE modified maximum likelyhood estimation technique

MVD median volume diameter of droplets, $\mu \mathrm{m}$

S

SHP

wing area, $\mathrm{ft}^{2}$

shaft horsepower

W

aircraft weight, ibs

$\alpha$

aircraft angle of attack, deg

B

aircraft yaw angle, deg

ambient static pressure divided by static pressure at standard day, sea level conditions 


$\begin{array}{ll}\delta_{a} & \text { aileron deflection, deg } \\ \delta_{e} & \text { elevator deflection, deg } \\ \delta_{f} & \text { flap deflection, deg } \\ \delta_{r} & \text { rudder deflection, deg } \\ \Delta & \text { denotes change in a parameter }\end{array}$

\section{Introduction}

The purpose of this paper is to present quantitative data showing the effects of icing on the performance and stability and control of a twin-engine, commuter-class aircraft. These data, which were acquired solely thirough flight testing, provide a unique association between measured icing cloud properties and the effect these properties have on aerodynamic coefficients and stability derivatives. This paper also presents the methods by which flight data were acquired and discusses the application of transient response flight test techniques for aircraft whose basic aerodynamics are altered by ice formations.

All aircraft are susceptible to icing when flying through clouds that contain super-cooled water droplets. The amount and type of ice forming on forward-facing aircraft surfaces is a func$t$ ion of several variables that include aircraft speed, cloud liquid water content, temperature, water droplet size distribution, airfoil or body geometry, angle of attack, and duration of the icing encounter. 1 The effects of icing on aircraft performance were measured by the NASA Lewis over a range of natural icing conditions as reported in Refs. 2 and 3. These measurements were made by employing stabilized level flight performance methods due to the limitations imposed by the type of flight instrumentation and data acquisition systems installed in the aircraft at that time. The data from these tests are currently being applied to the development of computer codes that predict aircraft performance losses due to icing.

Experience gained during these earlier flights indicated a need for more expedient performance flight testing techniques to reduce the effects of ice shape deterioration on the data. Accreted ice shapes, for example, were found to deteriorate through sublimation, melting, or erosion; and the test time available before these effects becarne significant depended largely on temperature, sunlight conditions, and flight speed. In a parallel development, NASA Lewis expanded its icing research program to include an investigation of the effects of icing on aircraft stability and control. This new initiative, along with the requirement to improve aircraft performance data acquisition techniques, resulted in the formulation of a flight program consisting of three major elements: static longitudinal stability and control flight tests in clear air with artificial ice shapes to gain experience with aircraft characteristics and help provide definition for natural icing tests; performance flight tests in natural icing conditions employing level acceleration and deceleration techniques; and, stability and control flight tests in natural icing conditions employing transient response flight test techniques.
Aircraft modifications for the static longitudinal tests with artificial ice shapes were accomplished in house. Data from these flights were also reduced and analyzed in-house. Modifications to the aircraft for the transient response flight tests and the methodology for data reduction and analysis were provided under contract to NASA Lewis by Kohlman Systems Research, Inc. (KSR), Lawrence, Kansas. The KSR system ${ }^{5}$ is capable of rapidly acquiring aircraft performance and stability and control data with a minimal number of flight test maneuvers. This system, described later in this report, uses performance modeling methods and modified maximum likelihood estimation (MMLE) techniques to perform an analysis of dynamic aircraft maneuvers and calculate aerodynamic coefficients and stability derivatives. This system, however, had never been used on an aircraft whose aerodynamic characteristics were altered by icing. Thus, one of the peripheral objectives of this program was to determine the utility of performance modeling and MMLE techniques for natural icing flight tests.

Only a portion of the data acquired with the KSR system was analyzed for this paper. Priority was given to an analysis of aircraft performance, longitudinal stability and control. Lateraldirectional data will be analyzed and presented in a follow-on report.

\section{The Research Aircraft}

The icing research aircraft is a modified DeHavilland $\mathrm{DH}-6$ Twin Otter. This aircraft, as shown in Fig. 1, is powered by two Pratt Whitney PT6A-20A gas turbine engines that deliver 550SHP each at standard day, sea level conditions. Aircraft weights, inertias, and dimensions are provided in Table I.

\section{Research Instrumentation Systems}

Icing Instrumentation and the Wing Stereo Camera System

The icing research aircraft measures cloud properties with several instruments as shown in Fig. 2, and the operation of these instruments is described in Ref. 6 . To eliminate redundancy, data only from three icing instruments were used to document icing cloud properties: liquid water content ( $L W C$ ) values were derived from the Rosemount Ice Detector; median volume droplet diameters (MVD) from the Foreward Scattering Spectrometer Probe (FSSP) produced by Particle Measuring Systems; and free air temperature from the Rosemount total air temperature probe. Stereo analyses of wing ice shapes were provided by the Arnold Engineering and Development Center (AEDC) from in-flight photographs (stereo pairs) taken with the stereo camera system (Fig. 3).

Instrumentation for Performance and Stability and Control Measurements

The icing research aircraft is equipped with control position transducers, a dynamic force wheel, and rudder pedal load cells as shown in Fig. 4. Airspeed, altitude, angle of attack (as referenced to the fuselage floor line), and angle of sideslip were measured by a heated Rosemount 858 probe as shown in Fig.5. This probe was 
flight calibrated for static source error by the trailing static cone method. ${ }^{8}$ Angle of attack was calibrated in flight with a floor-mounted inclinometer, and angle of sideslip was likewise flight calibrated against an inertially derived sideslip from the KSR gyro package. Control positions and forces were calibrated by comparing known inputs with recorded sensor outputs. Control position extremes and zero reference forces were recorded before and after each test flight. During static longitudinal flight testing with artificial ice shapes all flight parameters were recorded on a digital tape recorder and later reduced to engineering units for analysis.

\section{KSR Data Acquisition System}

Aircraft performance and stability and control for icing flights were measured by a modular data acquisition system (DAS) provided by KSR. The KSR DAS is a 12-bit system that records approximately 8.6 samples per second with all channels sampled within a 1 msec time interval and then recorded on tape. This effectively eliminates time skews due to sequential sampling. The DAS includes the computer, computer controls and display, tape recorder, and signal conditioning. The parameters recorded by this system for performance and stability and control measurements are listed in Table II.

\section{Flight Testing}

Static longitudinal flight test methods were employed to examine the effect of artificial ice shapes on stability margins. Transient response inethods were employed to examine aircraft performance and stability and control degradation after flight through natural icing conditions. Clear testing was required for both the static longitudinal and transient response methods to define baseline coefficients and derivatives for the clean aircraft.

\section{Clear Air Flight Testing}

Static longitudinal flight testing with artificial ice shapes attached to the horizontal tail. - An abbreviated flight test program with artificial ice shapes attached to the horizontal tail was conducted prior to the installation of the KSR system to help identify how aircraft handiing qualities and stability derivatives might be expected to change with natural ice accretions. This test program consisted of five research flights. One flight established a "no-ice" baseline data set while the remaining flights were flown with four characteristic ice types that simulated: surface roughness (initial stage of an icing encounter); rime ice (Fig. 6(a)); light glaze ice (Fig. 6(b)); and moderate glaze ice (Fig. 6(c)). The surface roughness condition (not shown here) was simulated by wrapping the leading edge of the horizontal tail with 50 grit sandpaper over an assumed impingement area. The simulated ice shapes in Figs. 6(a) to (c) were based upon photographs taken of the Twin 0tter tail on previous natural icing research flights. Environmental data from these flights were used in combinafion with the ice shape calculation procedures and the respective two-dimensional photograph to establish a cross sectional shape for testing.
Once the shape was determined, aluminum templates were fabricated and artificial "ice" was cut from styrofoam blocks with a hot wire. The artificial ice shapes were then glued to a thin, full-span, aluminum leading edge cap that conformed to the leading edge radius of the horizontal tail plane. The aluminum cap was secured by chordwise straps and clamped to the stabilizer hinge line. A typical installation for the moderate glaze ice shape is shown in Fig. 6(d).

Prior to flight testing, a basic operating weight and center of gravity (c.g.) was obtained by weighing the aircraft with all flight test instrumentation installed less fuel and crew. Individual crew members were then weighed, and their weights and seating locations were used to calculate a zero fuel weight and balance. It was found that by varying the seating locations of the cabin crew members, three evenly spaced c.g.'s could be obtained between 26 and 34 percent of the MAC. This rather expeditious procedure of varying c.g. in flight was then used to provide the necessary range of c.g.'s necessary for static longitudinal flight test maneuvers. Fuel weights recorded at the beginning and end of each maneuver were applied to the zero fuel weight calculation to obtain the average test weight and c.g. for the maneuver.

Classical longitudinal flight test maneuvers consisting of sawtooth climbs and descents and wind-up turns were employed to determine stickfixed and stick-free neutral and maneuver points. Al1 sawtooth maneuvers were flown at a nominal cruise power of 275 SHP/engine. Wind-up turns were accomplished at 120 KCAS and 103 KCAS. The test methods used to acquire these flight data are found in Ref. 9. With artificial ice shapes attached to the tail, special attention was given to the takeoff condition. Since no crew escape systems were available and the artificial ice shapes were not jettisonable, testing was approached very conservatively. All flights were thus restricted to the flaps-up configuration. During takeoff with each ice shape, nosewheel unstick speeds were noted relative to the baseline configuration; and positive stable response was verified through rotation and liftoff.

KSR performance and stability and control tests. - A complete performance and stability and control (MMLE) baseline (noniced) was derived for the Twin otter aircraft prior to the conduct of icing research flights. This baseline was acquired by conducting clear air tests with the aircraft configured as it would be for icing flight, i.e., with all externally mounted probes and sensors in place.

Transient response flight testing did not require maneuver repetition at different center of gravity locations, but a very accurate aircraft weight and center of gravity had to be known for each test maneuver. Therefore, weight and balance was obtained for each baseline flight by weighing the aircraft with all research equipment on board before and after fueling. Actual crew member weights and seating locations along with measured fuel burn off were then applied to determine aircraft weight and balance for each test point flown. The procedure of weighing the 
aircraft before and after fueling was not used for icing research flights since fuel weight calculations were adequately validated on the baseline flights.

Baseline performance flight test maneuvers consisted of level, full and partial power accelerations and decelerations, with a few stabilized points flown at selected airspeeds. The performance baseline was obtained in the cruise and noncruise (wing flaps extended) configurations. Throughout all performance maneuvers a constant weight to pressure $(\mathrm{W} / \delta)$ ratio was maintained; that is, as fuel was burned off, each test maneuver would be flown at successively higher altitude increments. Thus, a constant $\mathrm{W} / \mathrm{s}$ would be maintained from the arbitrary starting altitude.

Baseline MMLE flight test maneuvers consisted of longitudinal doublets, lateral directional doublets, and asymmetric power sideslips. Longitudinal doublets were performed in each of four wing flap configurations, i.e., $0^{\circ}, 10^{\circ}, 20^{\circ}$, and $37.5^{\circ}$. A range of four speeds were selected for each configuration to provide a reasonable spread of angles of attack without encountering buffet during the $1.5 \mathrm{~g}$ positive acceleration portion of the doublet. Each maneuver began with power set for level flight and the aircraft in trim. Longitudinal doublets were initially attempted at speeds as low as 110 percent of stall speed for a given weight and configuration. It was found through analysis that moderate stall buffet associated with the positive $(1.3$ to $1.5 \mathrm{~g})$ acceleration portion of the doublet would not allow MMLE to converge. Thus, the low-speed, longitudinal doublet maneuvers were restricted to speeds that would provide only very light buffet at approximately $1.5 \mathrm{~g}$ acceleration. This restriction generally required some experimentation on the part of the pilot to determine the slowest speed attainable as a function of test weight on baseline flights. For icing flights, this speed was found to be around 10 to 15 knots higher based upon test weight and the type and amount of ice on the wing.

All baseline longitudinal maneuvers were also flown at three discrete power settings, i.e., maximum continuous power, power for level flight, and an approximate zero thrust condition. These data enabled the isolation of power effects over the range of speeds tested when the aircraft was iced up. Baseline MMLE maneuvers were also repeated at two altitudes (approximately $7000^{\prime}$ and $13000^{\prime} \mathrm{MSL}$ ).

\section{Icing Research Flight Testing}

The basic approach used in the icing flight research experiment was to fly the aircraft through icing clouds with all ice protection systems (except engine inlet and propeller heaters) turned off. Icing cloud properties were continuousiy measured and recorded while the aircraft was maintained at a nominal cruise airspeed. Once a sufficient amount of ice had formed, the aircraft would be flown clear of the clouds and stereo photographs taken of the ice shapes, which had accreted on the right outboard wing panel. Dynamic flight maneuvers appropriate to performance or stability and control testing were then flown in a predetermined sequence. The sequence was established by: the mission objectives for that day; the required iced configurations obtainable through selective deicing; and the desired flap settings defined for a given set of data points.

Winter weather conditions in the Great Lakes region provide NASA Lewis with an excellent geographical location for natural icing research. "Lake effect" clouds formed by rising moist air over northeastern Ohio and western Pennsylvania provide an environmental situation where a high probability of icing exists even when it is not forecast. Lake effect clouds are generally stratoform-type clouds with tops below $10000^{\prime} \mathrm{MSL}$. This condition is ideal for the Twin Otter since it is not pressurized and use of crew oxygen is seldom required. It is also advantageous since the higher engine power available below $10000^{\prime}$ allows greater power margins for intentional airframe ice buildup.

Flight planning for icing research fights began with a systematic check on area forecasts, hourly weather observations, synopses, upper air soundings, terminal forecasts, and most important $1 y$, current pilot reports. In many cases, the FAA air traffic control facility in charge of airspace where icing was reported or forecast would be contacted by telephoine and asked to further query aircraft in their sector for temperature, sky condition, and icing. In many cases, this procedure resulted in a successful icing encounter whereas reliance on only weather and/or available pilot reports would have resulted in a mission cancellation.

Enroute to the known icing area, an attempt would be made to fly in the clear or at an aititude where no ice accretions could inadvertantly form on the aircraft. The purpose for this was to eliminate extraneous ice accretions on the airframe, which would not be considered representative of the measured icing encounter.

Testing with naturally accreted ice shapes required some special considerations. Upon exiting icing conditions, the aircraft would be flown so as to climb above or descend below the icing cloud. If testing was to be perfomed without cloud cover obscuring the sun, an attempt would be made to stay out of direct sunlight by placing the sun at the "six o'clock" position while flight test maneuvers were being performed. Also, the test matrix would be flown such that most slow speed data points would be accomplished first to further reduce the amount of ice erosion. Expeditious accomplishment of flight test maneuvers was another very critical factor in completing the test matrix before ice shape deterioration became significant. This required a very well-coordinated, organized, and concentrated effort on the part of the pilot and flight test engineer. While flight test maneuvers were being flown, other crew members recorded wing stereo photography, photo documentation of ice shapes on nonlifting surfaces, pilot comments, and flight clearances. Generally speaking, a complete aircraft performance test including level accelerations and decelerations to break out drag and lift decrements due to ice on the wings, horizontal tail, vertical tail, wing and landing gear struts, and the combined remainder of nonprotected components (radome, antennae, flap hinge brackets, etc.) was accomplished within 20 to $25 \mathrm{~min}$ after the icing 
encounter. For this period of time, ice accretions would usually retain their original shapes fairly well.

Stability and control testing was more involved. Here both longitudinal and lateral directional maneuvers had to be accomplished in several preplanned "iced" configurations. For reasons of flight safety, longitudinal maneuvers were performed only in the zero and ten degreee flap condition. Longitudinal and lateral directional doublets would also be repeated for each test point. Typically, 30 to 35 data points would be accomplished on a stability and control icing research flight, and the time required to complete these points would be approximately 30 to $40 \mathrm{~min}$. on some initial icing research flights, both performance and stability and control tests were accomplished; however, this procedure was discontinued in favor of $\mathrm{flights}$ dedicated to performance only or stability and control only. Combining performance and stability and control resulted in a less rigorous investigation of each phenomenon due to the limitation of time brought about by ice shape deterioration.

\section{Data Analysis}

A brief summary of data handling and analysis methods are given in this section of the report. The discussion is broken down into static and dynamic methods. No special modifications were made to the basic procedures in either method for the artificial or natural icing flight tests.

Static Longitudinal Flight Tests with Artificial Ice Shapes

Aircraft test weights and c.g. locatiouls were determined for each flight maneuver by applying fuel weights and moments to the zero fuel condition of the aircraft. Recorded flight parameters that included true airspeed, angle of attack, pressure altitude, static air temperature, elevator position, pilot elevator force, and vertical acceleration were calibrated, scaled, then tabu1 ated for each stabilized test point. Aircraft lift coefficient $C_{L}$ and normal force coefficient $\mathrm{C}_{N_{A}}$ corresponding to each of these stable points were then calculated. For sawtooth climbs and descents, $\delta_{e}$ versus $C_{L}$ and $F e / q$ versus $C_{L}$ were plotted for each c.g. tested. For wind-up turns, $\delta_{e}$ versus $C_{N_{A}}$ and $F_{e / q}$ versus $C_{N_{A}}$

were likewise plotted for each c.g. tested. Curves for each of these parameters were hand faired and, by the methods in Ref. 9, the location of the stick-fixed and stick-free neutral and maneuver points were determined.

Transient Flight Tests for Performance and Stability and Control

Flight data from appropriate dynamic maneuvers were reduced and analyzed on a Gould SEL 32/77 computer with a dual processor located at KSR in Lawrence, Kansas. A block diagram of the data management system is shown in Fig. 7 . This data management system was designed to function with the KSR Data Acquisition System.

The initial phase of the processing involved encoding the fiight tape to a SEL format, converting it to engineering units, and storing it on a disk and tape. The data then entered a preprocessor program in which corrections were made regarding position error of the airspeed system and location of the accelerometers away from the center of gravity. Also computed were the weight, center of gravity, moments and products of inertia, engine parameters (thrust, fuel flow, RPM, etc.) and other derived parameters that were needed for two or more of the succeeding analysis programs. Both the corrected and derived parameters were stored as a flight test data base (FTDB) along with the raw engineering units from which it was derived.

Aircraft performance was determined by an analysis program that took the thrust model of propulsion system, then accessed the FTDB, and calculated lift and drag coefficients by means of a basic set of equilibrium equations.

The MMLE analysis for the determination of aircraft stability derivatives was somewhat more complex. The MMLE method is based on an assumed mathematical model of the airplane where the stability and control derivatives represent the unknown parameters. Initial conditions and dynamic control inputs measured in flight were applied to the model with starting values of the unknown parameters, and the complete response of the model was then compared to that of the airplane. The difference was a response error. The MMLE program then changed the aerodynamic derivatives by a computational algorithm to reduce the response error. The new derivatives were then used in the math model to compute a new response error. This iteration procedure continued until a specified convergence criterion was met. The final derivatives represent airplane aerodynamic characteristics that minimize the error between airplane and mathematical model responses in the least squares sense.

Power effects on the stability derivatives were handled by establishing baseline derivatives as a function of flap setting and thrust coefficient. Thus when a stability and control maneuver was performed with ice on the aircraft, the degradation in a particular derivative would be determined relative to the baseline derivative calculated at the same power setting. All stability and control analyses from MMLE contained in this report are referenced to thrust coefficient.

\section{Results and Discussion}

Longitudinal Characteristics with Artificial Ice Shapes Applied to the Horizontal Tail

Control position and control force gradients from sawtooth climbs/descents and wind-up turns were examined for all five research flights. Each flight employing an artificial ice shape was compared to the baseline flight. Inspection of the plots indicated that only subtle differences existed between the baseline gradient data and gradient data from flights with surface roughness and the artificial rime shape. However, control force and control position gradients from the light and moderate glaze shapes displayed more recognizable trends away from the baseline. As would be expected, the moderate glaze ice shape provided the greater deviation of the two. 
Qualitatively, the aircraft was always strong positive stable during longitudinal maneuvers with each artificial ice shape. However, the moderate glaze ice shape did cause noticeably lighter pitch forces especially at lower speed. This observation was supported by the data; and thus, it was decided to calculate neutral and maneuver point locations for the moderate glaze ice shape and compare them to baseline data. These calculations were not made for the other artificial shapes.

Figures $8,9,10$, and 11 , which summarize the variations in neutral and maneuver point locations with $C_{L}$, provide comparisons between the baseline and moderate glaze ice shape. Figure 8 shows that on the average, approximately a 7 to 8 percent reduction in static margin occurs for the stick-fixed case. For the stick-free case, this reduction averages 3 to 5 percent as shown in Fig. 9 .

Data from wind-up turns also showed a reduction in maneuver margin. Figure 10, for example, shows that the stick-fixed maneuver point moves forward approximately 3 percent at the lower $C_{L}$ 's and as much as 12 to 15 percent at $C_{L}$ 's near stall. For the stick-free case shown in Fig. 11, the maneuver point moves forward approximately 15 percent at $C_{L}$ 's around 0.9 , and 7 percent or less near stall.

Generally, the data showed fairly consistent trends. Static and maneuvering margins were affected over the entire range of $C_{L}$ 's tested with the moderate glaze ice shape attached to the tail. These results are consistent with those reported in Ref. 10.

It should be pointed out that the static methods just described have many potential sources for error. Small variations in the measured parameters can be easily masked by instrument error, manual curve fitting, slope estimates, and extrapolation techniques. Because of this situation, it was possible to report with confidence only those results where the effects of icing were very pronounced. For example, Fig. 12 shows the relative differences between normalized force gradient curves measured on the baseline tail and the tail with the moderate glaze ice shape. These differences were of sufficient magnitude to report static margin degradation with confidence. On flights with surface roughness, rime, and light glaze shapes, the differences were more subtle and relative changes were hard to break out. It should be noted again that these tests were conducted with flaps up. Had the flaps been extended, the relative reduction in static margin would probably have been greater as described in Ref. 10, and the effects of the lesser ice shapes more pronounced.

Aircraft Performance and Stability and Control After Flight Through Natural Icing Conditions

General. - Ten icing research flights were flown in areas of northeastern Ohio, western Pennsylvania, and northwestern New York during the month of December 1985. Eight of these flights yielded research-quality data; and of these eight, four research flights were analyzed for this report. Discussions of results are referenced to assigned flight numbers. Flights $86-20$ and $86-21$ were selected for a full performance analysis.
Flight $86-20$ represented a moderate to heavy mixed icing condition and 86-21 represented a moderate glaze icing condition. Flights $86-16$ and 86-17 represented mixed icing conditions and were selected for longitudinal stability analysis. Flight 86-16 provided a comparison bewteen the baseline, all iced, then wing only iced condition, while flight 86-17 compared the baseline, all iced, then tail only iced condition. When looking at any flight data that shows "wings deiced," it must be remembered that the portions of the wing between the engine nacelles and fuselage are not protected; and, hence, approximately 17 percent of the wing span cannot be deiced. The full effects of this on performance and stability and control measurements cannot be assessed at this time. It is anticipated that the lateraldirectional data will be presented in a followon report.

Icing cloud data. - Icing cloud data recorded during natural icing flight tests are shown in Figs. 13 to 17 . The measurement of LWC, MVD, and temperature are subject to the following considerations:

a. LWC and MVD are not corrected for local droplet concentrations due to the presence of the aircraft in the icing cloud. A program is currently underway to calculate local droplet trajectories.

b. The Rosemount Ice Detector is an accretiontype device and, therefore, calculates an average LWC after a small amount of ice accumulates on the sensing portion of the probe. Rosemount Ice Detector plots of LWC tend to be somewhat jagged due to the coarse cycle time of the instrument.

c. Discontinuities in FSSP data generally occur for one of two reasons. Either the aircraft flys out of the cloud, or some component of the probe ices over and the instrument no longer functions. Portions of some FSSP plots show areas of missing data, which can be explained by knowledge of the flight profile through the icing conditions.

d. Sharp spikes in temperature profiles are "noise," such as those shown in Fig. 14. The jagged "sawtooth" dew point temperature profile as seen in Fig. 16 is an instrument problem.

A summary of these data, which are time averaged, appear in Table III. This summary provides a quick look at the overall icing conditions encountered and can be referenced to the icing certification requirements as contained in Federal Air Regulation (FAR) Part 25, Appendix C.11

Ice shape documentation. - In-flight photographs and stereo analyses of wing ice shapes are provided in Figs. 18 to 22. As in the icing cloud data, each figure is self-explanatory. The shape of the ice is critically important with respect to the performance degradation and stability and control effects on an aircraft. The "double-horned" ice shapes characteristic of glaze icing generally cause the greatest penalties in lift and drag. Temperature is one of the primary factors that influence the type of ice forming on a given aircraft surface. Generally, glaze ice forms at the warmer temperatures as shown by the icing and photographic data for flight 86-21 (Fig. 19), while colder temperatures cause mixed accretions 
(F)ights $86-20,86-16$, and $86-17$ shown in Figs. 18 , 20 , and 21 respectively), and rime accretions (Flight 86-23 shown in Fig. 22). Notice that mixed ice accretion shapes tend to be somewhat rectangular in cross section with small, longitudinally oriented, finger-like protrusions at the upper and lower edges, while rime ice takes on a more wedge-shapped appearance. Photographs taken on Flight 86-23 were included only to provide an example of rime ice. Stability and control analyses for this flight are forthcoming in a future report.

Aircraft performance. - Aircraft performance measurements were obtained for the baseline (noniced) condition with flaps set at $0^{\circ}, 10^{\circ}, 20^{\circ}$, and $37.5^{\circ}$; however, only the $0^{\circ}$ flap data was actually carried beyond the flight test data base level and plotted in coefficient form. It was decided that only iced aircraft performance in the $0^{\circ}$ flap cruise configuration would be analyzed for this report.

Aircraft performance is presented in terms of lift slopes and drag polars and may be found in Figs. 23 to 26 . A pitching moment curve, which is also derived from level accelerations and decelerations and an MMLE analysis, is provided in Fig. 27. Because of the rather substantial effect power has on these data, all icing flight tests were conducted at two basic power settings and referenced to the respective baseline plot. Level accelerations were performed at 40 psi engine torque and 96 percent propeller RPM; and level decelerations at 15 psi engine torque at the same RPM. These power settings approximate maximum and minimum thrust conditions, and, thereby, provide the full range of power effects on aerodynamic performance coefficients. Baseline and icing flight data are then compared at these power settings, and the absolute magnitudes of aircraft performance degradation due to the aerodynamic effects of icing are readily determined. In this regard, the method of level accelerations and decelerations has an advantage over the steady power for level flight technique since the latter technique incorporates a power effect in each discrete measurement, which is more difficult to account for.

Transients during the initial phase of each acceleration or deceleration maneuver are generally disregarded in the analysis. Normally, this is not too much of a problem; however, when the aircraft is iced up, the speed envelope is smaller due to a higher stall speed and a lower maximum speed. As a result, a relatively smaller range of coefficient values are calculated. This effect is seen throughout the performance analysis and identifed by the boundary labeled "ice data range." This boundary reflects the average level flight speed envelope attainable for the type of icing encountered on a particular flight less that which was "clipped" during the initial transient.. Note that the drag polar data is extrapolated to a $C_{L}=0$.

All the performance plots show that 1 ift curves and drag polars are steeper and of higher absolute value at 40 psi torque than at 15 psi torque. This is an expected occurrence as the propeller wake energizes the wing boundary layer to increase lift and also increases drag due to the wash of the slipstream over the engine nacelle, wing, and horizontal tail. The differences in lift and drag coefficients at the two power settings are essentially a maximum power effect. What is also interesting is that lift and drag decrements, which were broken out by selectively deicing the aircraft, remain relatively the same percentage wise at both high and low power settings. For example, referring to Fig. 23 and the summary performance data in Table IV for flight 86-20, the total degradation in lift coefficient at an arbitrary angle of attack of $6^{\circ}$ is approximately 7 percent with 40 psi torque, and 8 percent with $15 \mathrm{psi}$ torque; and the individual contributions of each iced component are nearly the same at both power settings. The drag polars in Fig. 24 along with summary data in Table IV for the same flight show similar results. Percentage wise, the drag decrements were about the same at the high and low power settings. These observations also hold for performance data seen in Figs. 25 and 26 . This is significant because the relative magnitude of 1 ift and drag decrements due to ice appear independent of power within the linear portion of the flight envelope. On the other hand, the absolute magnitude of these decrements are dependent on power effects; and it would seem that these observations would hold for any conventionally configured, multiengine, propeller aircraft. This will become an important consideration in the development and validation of aircraft performance prediction codes, which must take into account power effects.

The flight data point out that the shape of aircraft ice accretions on both lifting and nonlifting surfaces is the most important factor influencing performance. For example, the icing encounter on flight $86-20$ lasted 54 min at an average $L W C$ of $0.46 \mathrm{gm} / \mathrm{m}^{3}$ while the encounter on flight 86-21 lasted 45 min at an approximate average LWC of $0.2 \mathrm{gm} / \mathrm{m}^{3}$. Though the average MVD on each flight was approximately 14 to $15 \mu \mathrm{m}$, the temperature differed by $4.5^{\circ} \mathrm{C}$. The difference in temperature resulted in a glaze-type ice formation on flight 86-21. The encounter on this flight was 9 min shorter than on the previous flight 86-20 and the LWC less by a factor slightly greater than two; yet the overall drag increase was about 15 to 20 percent higher. The lift curves don't show as large a variation from one flight to the other; however, it must be remembered that $C_{L}$ measurements made at a $6^{\circ}$ angle of attack are still below stall buffet speeds. Previous experience and data appearing in Refs. 2 and 3 show that the lift curve for the glaze ice condition flattens more rapidly than those for other ice shapes at higher angles of attack.

Longitudinal Stability and control characteristics with ice - Referring now to the pitching moment curves in Fig. 27 , it becomes imnediately apparent that power effects literally overwhelm any changes in the static pitching moment parameter due to icing. Note the difference in baseline slopes at 15 psi torque as opposed to the $40 \mathrm{psi}$ torque curve. The high thrust line of the engines in combination with propeller slipstream effects over the wing and tail greatly increase the static longitudinal stability parameter $C_{m_{\alpha}}$ as shown in Fig. 27(a). At the 15 psi torque setting, the effect of icing on this parameter was not seen in the data from either flight $86-20$ or $86-21$. At the 40 psi torque pressure setting, small reductions were measured 
in $C_{m_{\alpha}}$ on both icing flights. However, the data from both flights was indistinguishable; that is, for the same iced configuration, the "mixed" type ice shape and the "glaze" type ice shape gave the same result. It was for this reason that the data from both flights $86-20$ and $86-21$ were lumped onto the single plot.

Comparing baseline and iced slopes of $C_{m}$ versus $\alpha$, the static pitching moment of the aircraft is reduced approximately 13 percent in the all-iced, power-on case and approximately 9.9 percent after the wings are deiced. (Remember that the inboard portions between the engine nacelles and fuselage are not protected.) This seems to be about the right order of magnitude since static longitudinal tests with artificial ice showed an average 5 percent reduction in stick-fixed static margin at a lower power setting. Since the static pitching moment parameter is proportional to the static margin, these results appear reasonable.

Icing effects on longitudinal stability derivatives for the baseline aircraft were compared with those obtained after a natural icing encounter.

Flights $86-16$ and $86-17$ were flown in mixed conditions, and the ice shapes which formed on the aircraft during each flight were similar. This was an extremely fortunate circumstance as these similarities allowed a comparative analysis of the two flights. On flight 86-16 the effect of ice was studied for the all-iced and tail-onlyiced configurations at both zero and ten degree flap settings. On flight 86-17 the effect of ice was also studied on the all-iced aircraft; however, this time the tail was deiced and the effects of wing ice alone were evaluated at the zero and ten degree flap settings. Looking first at the zero degree flap results for flights $86-16$ and 86-17 in Figs. 28 and 30 , the all-iced aircraft showed an average 10 percent degradation in elevator power $\mathrm{C}_{\mathrm{m}_{\mathrm{e}}}$, and elevator effectiveness, $\mathrm{C}_{\mathrm{L}_{\delta_{e}}}$.

When the tail only was iced (Fig. 28), this degradation averaged around 8.5 percent; and when the wing only was iced (Fig. 30), a rather small 2 percent degradation was calculated. When flaps were lowered ten degrees, the all-iced degradation in these coefficients increased to a more significant 15 to 16 percent as shown in Figs. 29 and 31 . It was interesting that wing ice, which had little effect on the derivatives with flaps up, now caused a degradation in elevator power and elevator effectiveness of approximately 9 percent.

Figure 32 shows the effects of ice on a combined pitch damping state coefficient whose individual componets were not identified by MMLE. It was found in the flaps-up case, icing had no effect on this coefficient; however, when flaps were lowered $10^{\circ}$ and ice was on the wings, tail, or both, this coefficient was degraded approximately 23 percent. Data from flights $86-16$ and $86-17$ provided identical results and were, therefore, plotted on the one figure. A similar result was seen in Fig. 33 for the combined state coefficient $\left(C_{L_{q}}+C_{L_{\alpha}}\right)$. With flaps up, no degradation was seen in this coefficient for either flight 86-16 or 86-17. However, when flaps were lowered $10^{\circ}$, a 25 percent degradation was seen for both flights in any iced configuration. The data from both flights are shown on Fig. 33.

\section{Conclusions}

The performance of an aircraft after flight through measured natural icing conditions is primarily affected by the shape of ice forming on forward-facing airframe components. Performance modeling methods, combined with dynamic maneuvers, was found to be a very practical and expeditious way of measuring lift, drag, and pitching moment decrements in natural icing conditions. The acceleration and deceleration maneuvers enabled the breakout of power effects, which in an absolute sense, were determined to be very substantial for a propeller-driven aircraft. A corollary to this fact was the observation that performance decrements were, percentage-wise, the same, in a relative sense, over a wide range of power settings. This was a very important finding with respect to its impact on the validation of performance degradation codes and to other applications such as the development of flight simulator software for icing scenarios.

Ice accretions (real and artifical) degraded static and maneuver margins, elevator control derivatives, and pitching moment slopes throughout the flight envelope. Elevatoi control derivatives were more affected at higher tail downwash angles resulting from wing flap extension.

The use of the KSR system to acquire performance and stability and control data was found to be extremely useful for natural icing flight tests. The rapidity with which data can be acquired by transient response techniques makes this system a viable method in a time-critical test environment.

One of the long range objectives of the NASA Lewis icing research program is to provide methodologies that can predict aircraft performance losses and stability and control effects on an aircraft. This technology would have direct application in: aircraft design; conducting sensitivity studies for advanced flight control systems on relaxed stability aircraft; performing failure effects modes analyses for ice protection systems; generating simulator software for pilot training; and in improving aircraft icing certification criteria for better operational safety. The test results reported herein are an initial step in that direction. Advancements in this technology will require a more rigorous approach to the problem.

\section{References}

1. Bowden, D.T., Gensemer, A.E., and Skeen, C.A., "Engineering Summary of Airframe Icing Technical Data," General Dynamics/Convair, San Diego, CA, Technical Report ADS-4, Mar. 1964 .

2. Ranaudo, R.J., Mikkelsen, K.L., Mcknight, R.C., and Perkins, P.J., Jr., "Performance Degradation of a Typical Twin Engine Commuter Type Aircraft in Measured Natural Icing Conditions," NASA TM-83564, 1984. 
3. Mikkelsen, K.L., McKnight, R.C., Ranaudo, R.J., and Perkins, P.J., Jr., "Icing Flight Research: Aerodynamic Effects of Ice and Ice Shape Documentation with Stereo Photography;" NASA TM-86906, 1985.

4. Shaw, J.J., "Progress Toward the Development of an Aircraft Icing Analysis Capability," NASA TM-83562, 1984.

5. Renz, R.L. and Schweiknard, W.G., "A Miminum Approach to Flight Testing," Flight Testing Evolution and Revolution, Society of Flight Test Engineers, 1985.

6. Ide, R.F. and Richter, G.P., "Evaluation of Icing Cloud Instruments for 1982-83 Icing Season Flight Program," AIAA Paper 84-0020, Jan. 1984.

7. Mcknight, R.C., Palko, R.L., and Humes, R., "In-Flight Photogrammetric Measurement of Wing Ice Accretions," AIAA Paper 86-0483, Jan. 1986.
8. Crowley, L.D., "Trailing Cone Systems Applications," Douglas Aircraft Company; TM-GEN-4158, Aug. 1967.

9. Perkins, C.D., "Static Longitudinal Stability and Control," pp. 3:1-3:29, and Johnson, H.I., "Flight Testing Aircraft for Longitudinal Maneuvering Characteristics," pp. 4:1 - 4:31; AGARD Flight Test Manual, Vol. II, Stability and Control, edited by C.D. Perkins, 2nd revised ed.; Pergamon Press, 0xford, 1963.

10. Ingelman-Sundberg, M. and Trunov, O.K., "On the Problem of Horizontal Tail Stall Due to Ice, "Swedish Soviet Working Group on Scientific-Technical Cooperation in the Field of Flight Safety, Report JR-3, Feb. 1985.

11. "Ice Protection," Airworthiness Standards: Transport Category Airplanes, F.A.A. Regulations, Part 25, Section 25.1419, and Appendix C, 1974. 
TABLE I. - AIRCRAFT CHARACTERISTICS

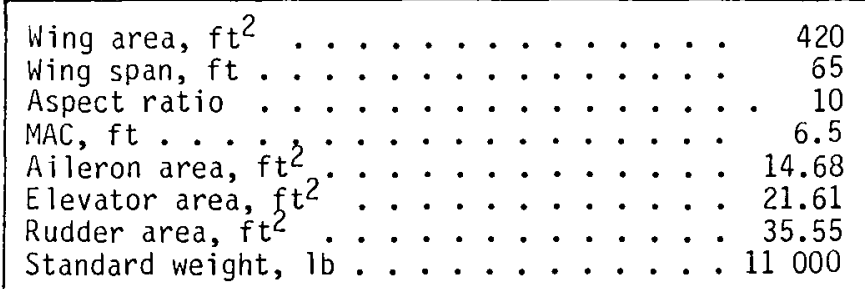

Moments of inertia at standard weight during icing flight test period:

$I_{x x}$, slug $f^{2}$............... 16237

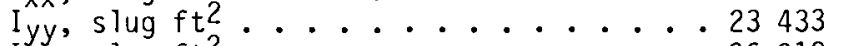

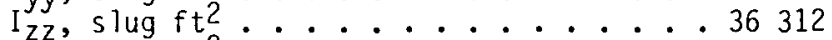

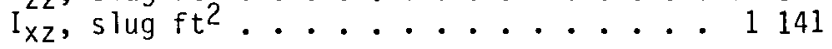


TABLE II. - KSR DATA ACQUISITION SYSTEM

[Recorded Data, NASA Twin Otter DHC-6-004.]

\begin{tabular}{|c|c|c|c|}
\hline $\begin{array}{c}\text { Variable } \\
\text { number }\end{array}$ & Variable & Variable name & Units \\
\hline $\begin{array}{l}1 \\
2 \\
3 \\
4\end{array}$ & $\begin{array}{l}\text { FILCNT } \\
\text { BLKCNT } \\
\text { ESB } \\
\text { ASB }\end{array}$ & $\begin{array}{l}\text { File counter } \\
\text { Block counter } \\
\text { Engineer's status BYTE } \\
\text { Aircraft status BYTE } \\
\text { Pause event } \\
\text { Rosemount heat } \\
\text { Gear position } \\
\text { Gyro erection marker } \\
\text { Pilot event }\end{array}$ & - \\
\hline 5 & Time & Time & $\sec$ \\
\hline 6 & & Longitudinal acceleration & $G$ \\
\hline $\begin{array}{l}7 \\
8\end{array}$ & & Z-direction acceleration & $G$ \\
\hline 9 & Pitch-rate & Pitch rate & $\mathrm{deg} / \mathrm{sec}$ \\
\hline $\begin{array}{l}10 \\
11\end{array}$ & $\begin{array}{l}\text { Roll-rate } \\
\text { Yaw-rate }\end{array}$ & $\begin{array}{l}\text { Pitch rate } \\
\text { Yaw rate }\end{array}$ & $\begin{array}{l}\mathrm{deg} / \mathrm{sec} \\
\mathrm{deg} / \mathrm{sec}\end{array}$ \\
\hline 12 & Pitch-att & Pitch attitude & deg \\
\hline $\begin{array}{l}13 \\
14\end{array}$ & $\begin{array}{l}\text { Roll-att } \\
\text { Delp-alpha }\end{array}$ & $\begin{array}{l}\text { Ro11 attitude } \\
\text { Pressure alpha }\end{array}$ & $\begin{array}{l}\text { deg } \\
\text { psf }\end{array}$ \\
\hline 15 & Delp-beta & Pressure beta & psf \\
\hline $\begin{array}{l}16 \\
17\end{array}$ & $\begin{array}{l}\text { Delp-ref } \\
\text { Delta-A-L }\end{array}$ & $\begin{array}{l}\text { Pressure reference } \\
\text { Aileron deflection }\end{array}$ & $\begin{array}{l}\text { psf } \\
\text { deg }\end{array}$ \\
\hline $\begin{array}{l}18 \\
19\end{array}$ & Delta-E & Elevator deflection & \\
\hline 20 & Delta-R & Rudder deflection & deg \\
\hline 21 & Flap & Flap position & deg \\
\hline $\begin{array}{l}32 \\
33\end{array}$ & $\begin{array}{l}\text { Diff-press } \\
\text { Air-temp }\end{array}$ & $\begin{array}{l}\text { Differential pressure } \\
\text { Indicated total } \\
\text { temperature }\end{array}$ & $\begin{array}{c}\operatorname{psf} \\
\operatorname{deg} / K\end{array}$ \\
\hline 34 & Inert-vref & $\begin{array}{l}\text { Vertical gyro reference } \\
\text { voltage }\end{array}$ & volt \\
\hline $\begin{array}{l}35 \\
36\end{array}$ & $\begin{array}{l}\text { Stat-press } \\
\text { Cpt-vref }\end{array}$ & $\begin{array}{l}\text { Static pressure } \\
\text { Reference voltage }\end{array}$ & $\begin{array}{l}\text { psf } \\
\text { volt }\end{array}$ \\
\hline 37 & Battery-A & Reference battery board 1 & volt \\
\hline 39 & Fuel-used & Fuel used & $1 \mathrm{~b}$ \\
\hline 40 & & Pilot aileron force & lb \\
\hline 41 & & Pilot elevator force & ib \\
\hline 42 & PRF-L & Pilot rudder force, left & lb \\
\hline $\begin{array}{l}43 \\
49\end{array}$ & $\begin{array}{l}\text { PRF-R } \\
\text { N1-L }\end{array}$ & $\begin{array}{l}\text { Pilot rudder force, right } \\
\text { Gas generator RPM-N1, left }\end{array}$ & $\begin{array}{c}1 \mathrm{~b} \\
\text { percent }\end{array}$ \\
\hline $\begin{array}{l}50 \\
51\end{array}$ & $\begin{array}{l}\text { N1-R } \\
\text { PROP-RPM-L }\end{array}$ & $\begin{array}{l}\text { Gas generator RPM-N1, right } \\
\text { Propeller RPM. left }\end{array}$ & $\begin{array}{l}\text { percent } \\
\text { percent }\end{array}$ \\
\hline $\begin{array}{l}52 \\
53\end{array}$ & $\begin{array}{l}\text { PROP-RPM-R } \\
\text { Torque-L }\end{array}$ & $\begin{array}{l}\text { Propeller RPM, right } \\
\text { Engine torque pressure, }\end{array}$ & $\begin{array}{c}\text { percent } \\
\text { psi }\end{array}$ \\
\hline 54 & Torque-R & $\begin{array}{l}\text { Engine torque pressure, } \\
\text { right }\end{array}$ & psi \\
\hline 55 & Fuel-Flo-L & $\begin{array}{l}\text { Indicated fuel flow left } \\
\text { engine }\end{array}$ & $\mathrm{lb} / \mathrm{hr}$ \\
\hline 56 & Fue 1-Flo-R & Indicated fuel flow right & $\mathrm{lb} / \mathrm{hr}$ \\
\hline 57 & Fuel temp-L & $\begin{array}{l}\text { Fuel temperature left } \\
\text { enqine- }\end{array}$ & $\operatorname{deg} / K$ \\
\hline 58 & Fuel temp-R & $\begin{array}{l}\text { Fuel temperature right } \\
\text { engine }\end{array}$ & $\operatorname{deg} / K$ \\
\hline 64 & Johns-wil1 & $\begin{array}{l}\text { Liquid water content } \\
\text { indicator }\end{array}$ & volt \\
\hline 65 & Leigh & Ice detector unit & volt \\
\hline 66 & Rosemont & Ice detector unit & volt \\
\hline 67 & & Dew point hygrometer & volt \\
\hline 71 & Battery-B & Reference battery board 2 & volt \\
\hline
\end{tabular}


TABLE III. - SUMMARY OF AVERAGED ICING CLOUD DATA FOR PERFORMANCE ANO STABILITY AND CONTROL

\begin{tabular}{|c|c|c|c|c|c|c|c|c|c|}
\hline $\begin{array}{c}\text { Flight } \\
\text { number }\end{array}$ & $\begin{array}{c}\text { Start } \\
\text { time }\end{array}$ & $\begin{array}{c}\text { End } \\
\text { time }\end{array}$ & $\begin{array}{c}\text { Alt., } \\
\text { PA, } \\
\mathrm{ft}\end{array}$ & $\begin{array}{c}\text { TAS, } \\
\mathrm{Kts}\end{array}$ & $\begin{array}{c}\text { AOA, } \\
\mathrm{deg}\end{array}$ & $\begin{array}{c}\text { Static } \\
\text { temperature, } \\
{ }_{\mathrm{C}}\end{array}$ & $\begin{array}{c}\text { Dew } \\
\text { point, } \\
{ }_{\mathrm{C}}\end{array}$ & $\begin{array}{c}\text { Average } \\
\text { LWC, } \\
\mathrm{g} \cdot \mathrm{m}^{-3}\end{array}$ & $\begin{array}{c}\text { Average } \\
\text { MVD, } \\
\mu \mathrm{m}\end{array}$ \\
\hline 16 & $14: 32: 58$ & $15: 12: 18$ & 8060 & 138.6 & 1.4 & -8.0 & ---- & 0.25 & 19 \\
17 & $10: 08: 28$ & $10: 27: 18$ & 7309 & 135.0 & 1.6 & -7.2 & -8.1 & .33 & 21 \\
20 & $12: 42: 48$ & $13: 36: 58$ & 6163 & 127.3 & 1.8 & -9.5 & -10.0 & .46 & 14 \\
21 & $09: 55: 38$ & $10: 40: 38$ & 4315 & 130.8 & 1.6 & -5.0 & -4.8 & $\sim .20$ & 15 \\
23 & $10: 13: 38$ & $11: 11: 48$ & 4330 & 136.4 & 0.5 & -0.5 & -10.7 & .30 & 10 \\
\hline
\end{tabular}

TABLE IV. - SUMMARY OF ESTIMATED PERFORMANCE LOSSES DUE TO ICING

\begin{tabular}{|c|c|c|c|c|c|c|c|}
\hline \multirow[t]{3}{*}{$\begin{array}{l}\text { Flight } \\
\text { number }\end{array}$} & \multirow[t]{3}{*}{$\begin{array}{l}\text { Ice } \\
\text { type }\end{array}$} & \multirow[t]{3}{*}{$\begin{array}{l}\text { Airframe component(s) isolated } \\
\text { by selective deicing }\end{array}$} & \multirow[t]{3}{*}{ Parameter } & \multicolumn{2}{|c|}{$\begin{array}{c}\text { Total effect on } \\
\text { parameter, } \\
\%\end{array}$} & \multicolumn{2}{|c|}{$\begin{array}{c}\text { Component contribution } \\
\text { to total effect, } \\
\%\end{array}$} \\
\hline & & & & \multicolumn{4}{|c|}{ Engine torque } \\
\hline & & & & 40 psi & 15 psi & 40 psi & 15 psi \\
\hline $86-20$ & glaze & $\begin{array}{l}\text { All components } \\
\text { Wings } \\
\text { Tail, wing strut, and main } \\
\text { gear strut } \\
\text { Miscellaneous components } \\
\text { (flap hinges, antenna, etc.) } \\
\text { All components } \\
\text { Wing } \\
\text { Tail, wing strut, and main } \\
\text { gear strut } \\
\text { Miscellaneous components }\end{array}$ & $\begin{array}{c}C_{L} \\
\left(\alpha=6^{\circ}\right)\end{array}$ & -7 & -8 & $\begin{array}{l}-- \\
36 \\
36 \\
28 \\
47 \\
24 \\
29\end{array}$ & $\begin{array}{l}-- \\
40 \\
27 \\
33\end{array}$ \\
\hline $86-21$ & Mixed & $\begin{array}{l}\text { All components } \\
\text { Wing } \\
\text { Horizontal stabilizer } \\
\text { Vertical stabilizer wing strut } \\
\text { and main gear strut } \\
\text { Miscellaneous components } \\
\text { All components } \\
\text { Wing } \\
\text { Vertical stabilizer } \\
\text { Horizontal stabilizer } \\
\text { Wing strut and main gear strut } \\
\text { Miscellaneous components }\end{array}$ & 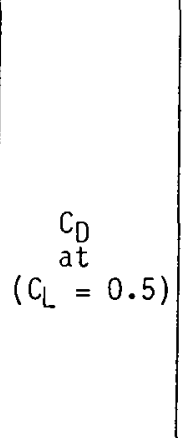 & +36 & +30 & $\begin{array}{r}36 \\
26 \\
23 \\
\\
15 \\
30 \\
16 \\
9 \\
16 \\
29\end{array}$ & $\begin{array}{l}40 \\
27 \\
20 \\
\\
13 \\
28 \\
17 \\
13 \\
17 \\
26\end{array}$ \\
\hline
\end{tabular}




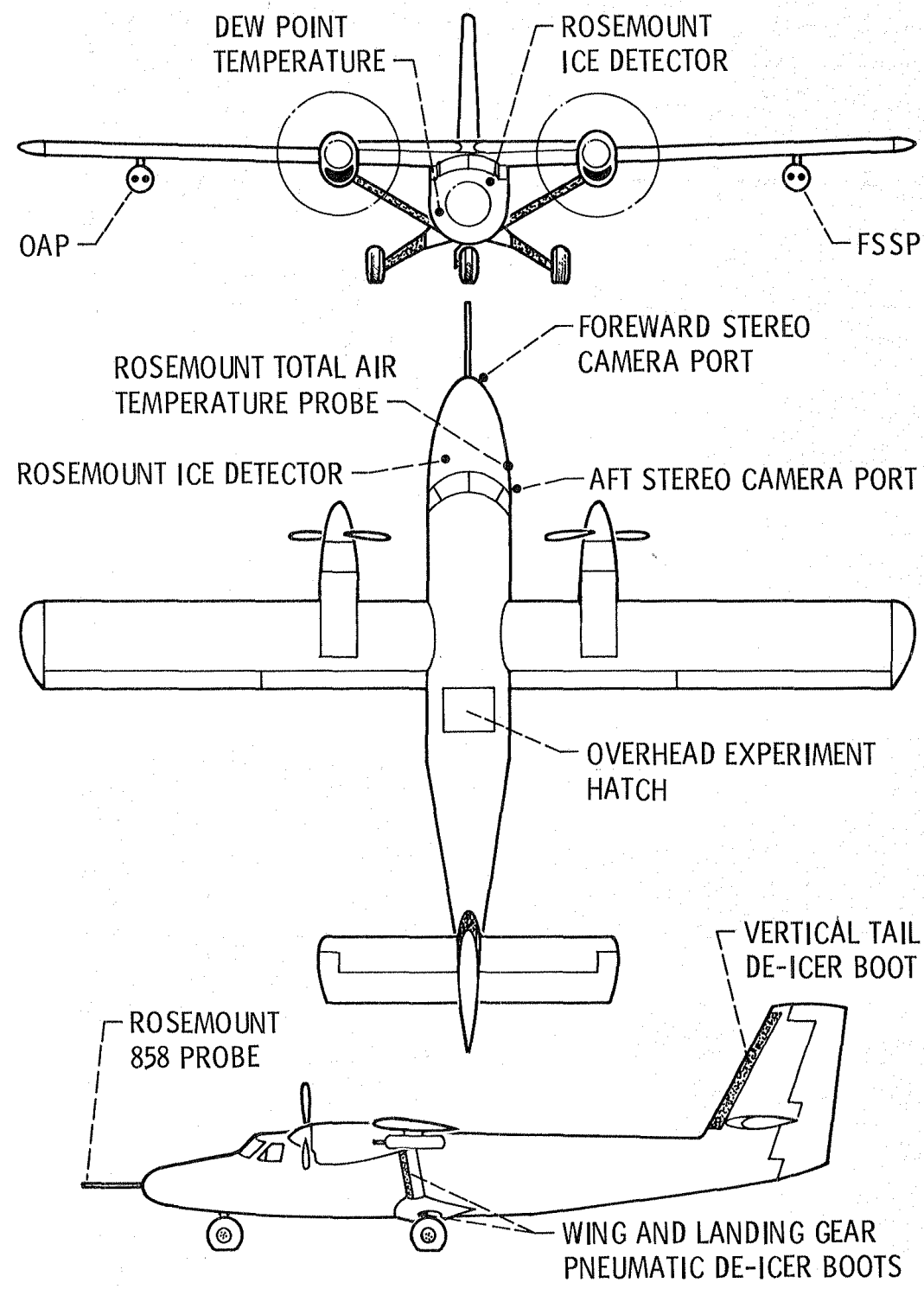

Figure 1. - NASA Lewis Research Center icing research aircraft and locations of icing instruments. 


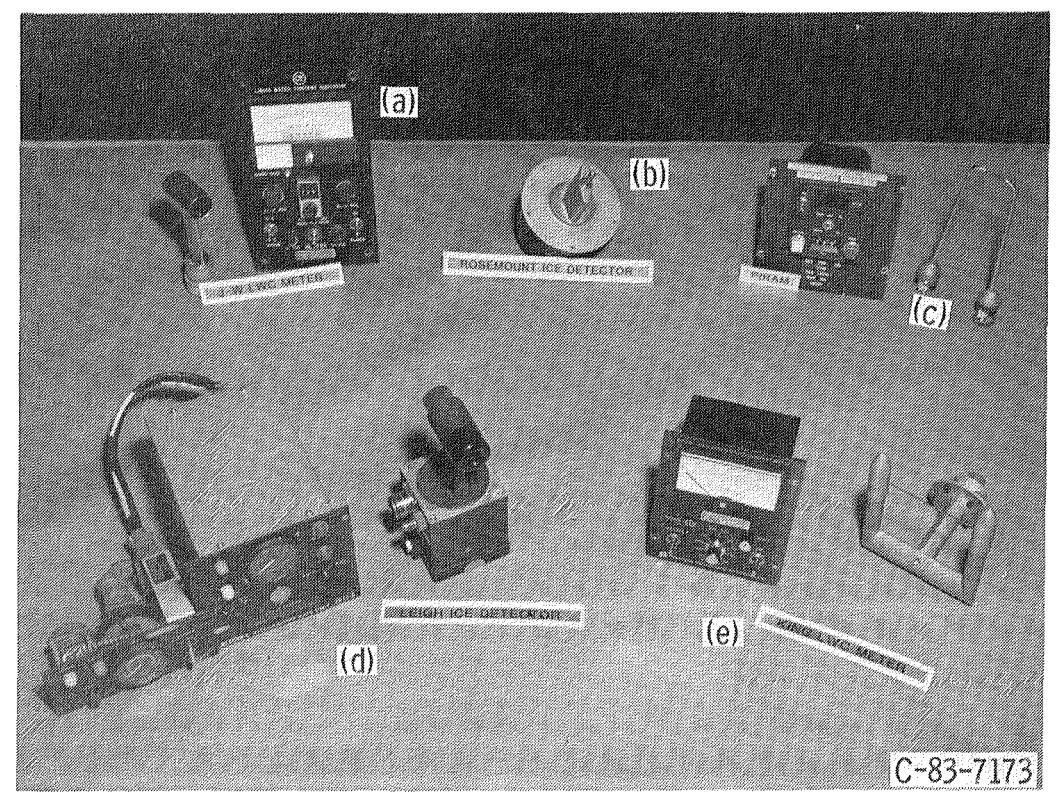

(a) Liquid water content instruments (a) Johnson Williams, (b) Rosemount ice detector, (c) pressure ice rate and accretion meter, (d) Leigh ice detector, (e) CS IRO-KING.

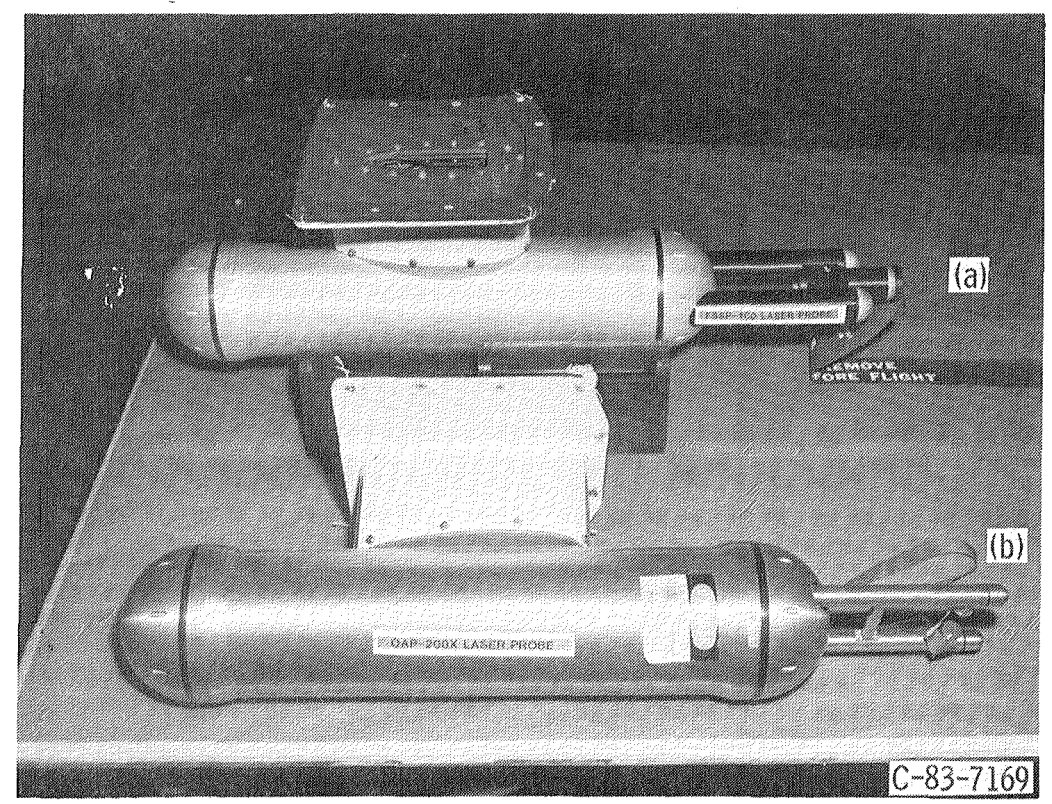

(b) Droplet sizing instruments (a) forward scattering spectrometer probe, (b) optical array probe.

Figure 2. - Icing instrumentation. 

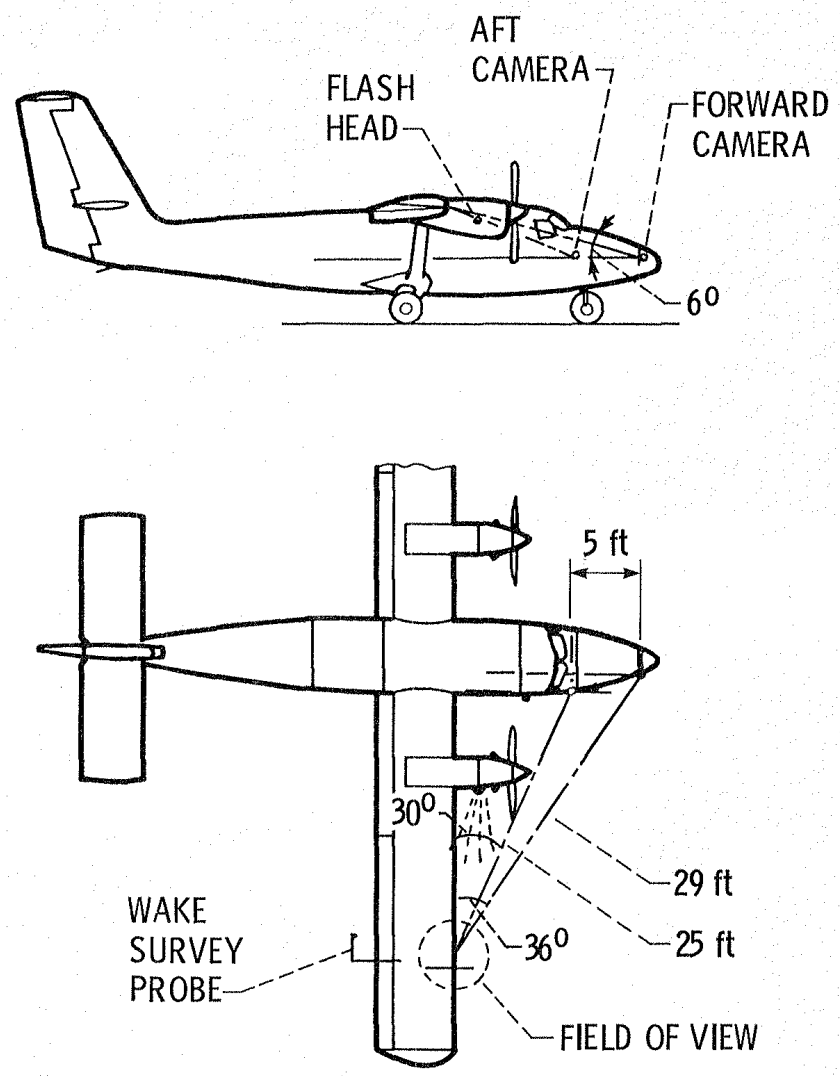

Figure 3. - Wing stereo camera system layout. 


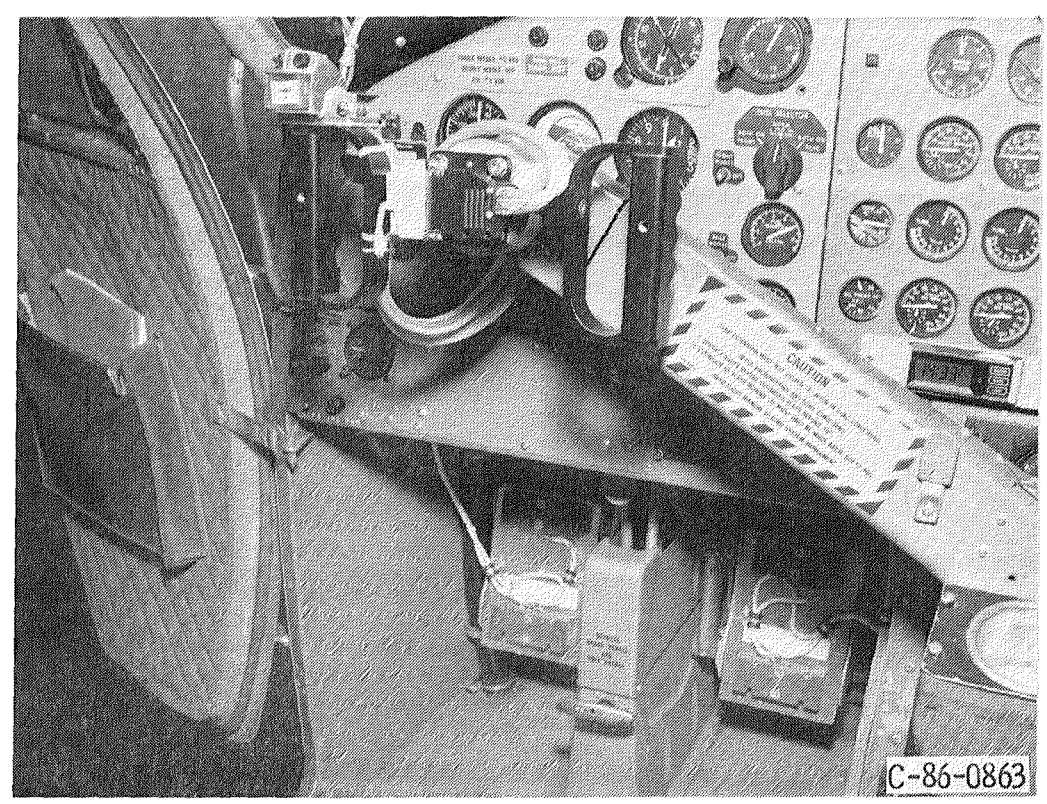

(a) Pilot's dynamic force wheel.

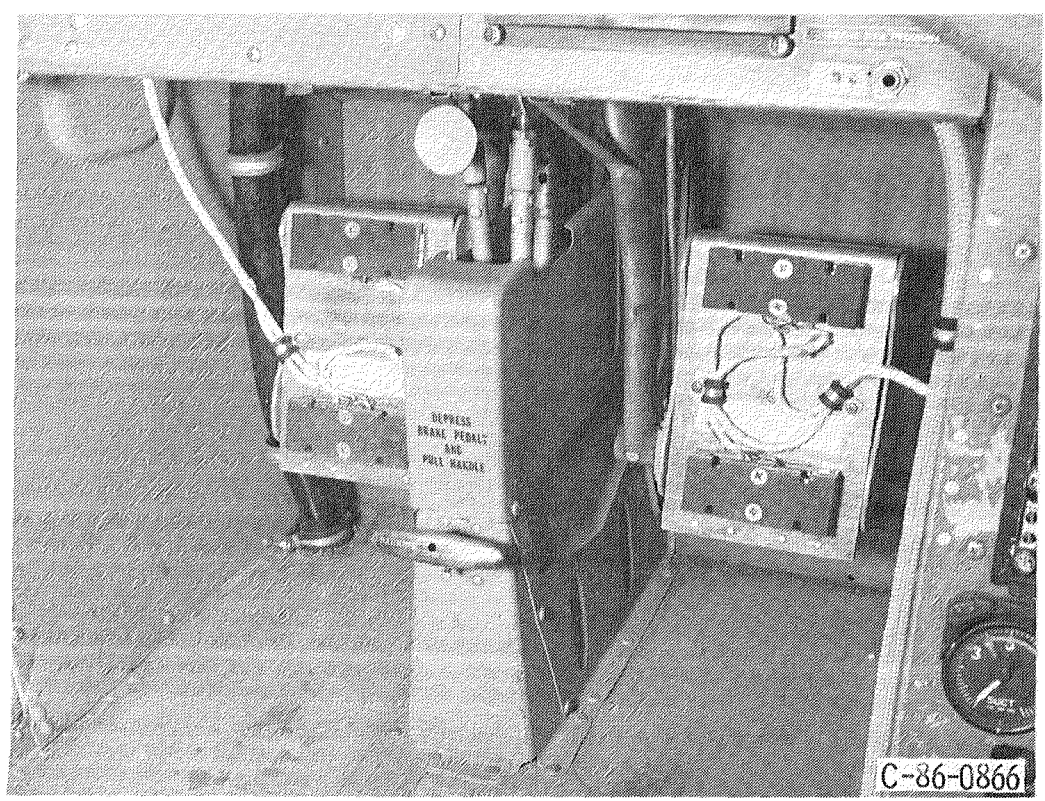

(b) Rudder pedal load cells.

Figure 4. - Dynamic force wheel and rudder pedal load cells for preformance and stability and control measurements. 


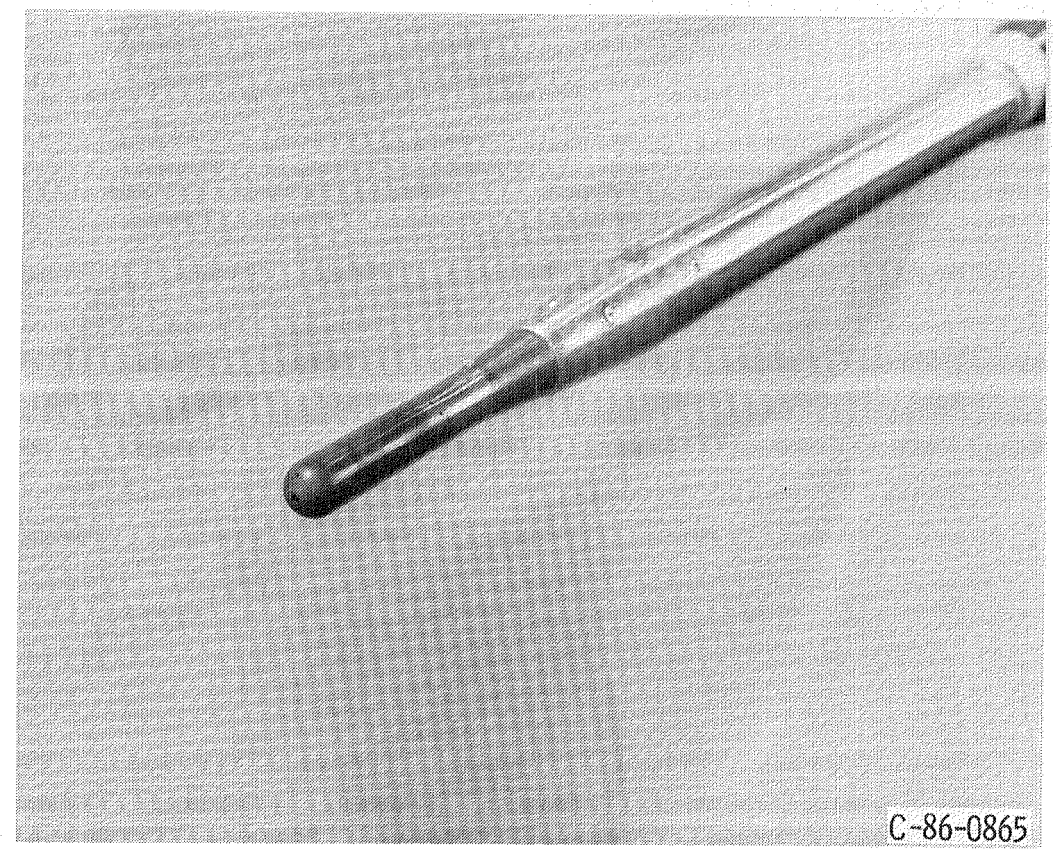

Figure 5. - Heated Rosemount 858 flow angle sensor to measure airspeed, altitude, angle of attack, and sideslip. 


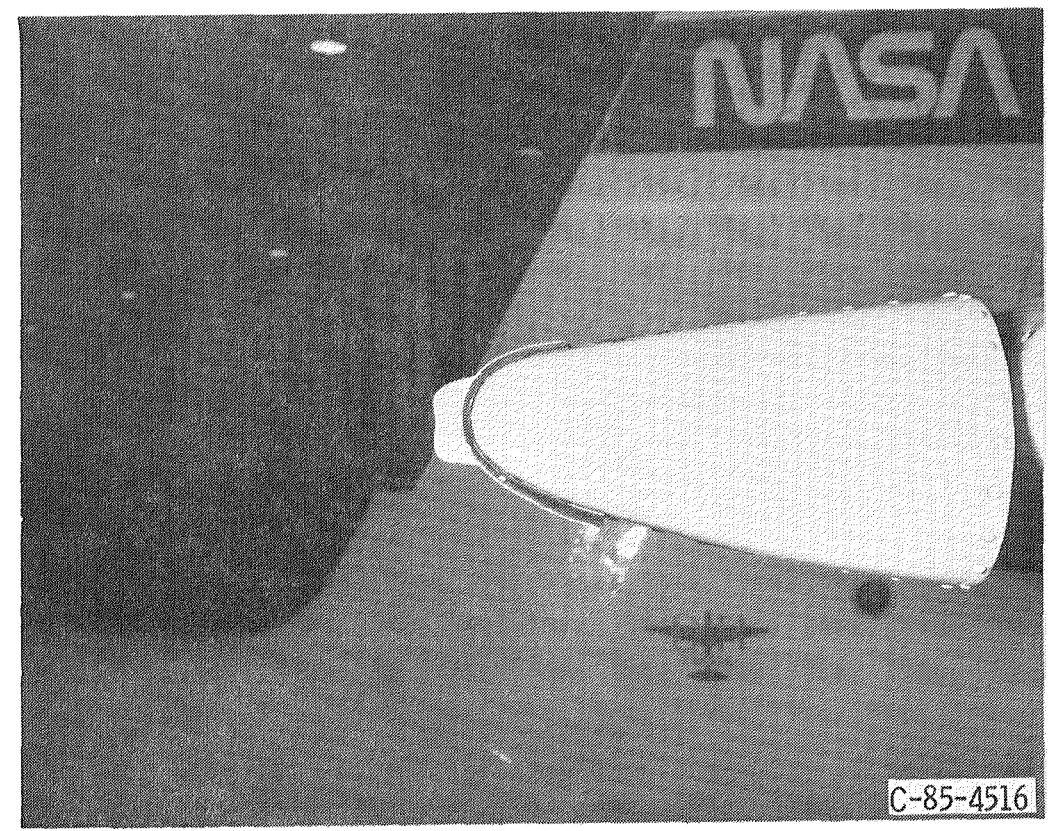

(a) Artificial "Rime" ice shape.

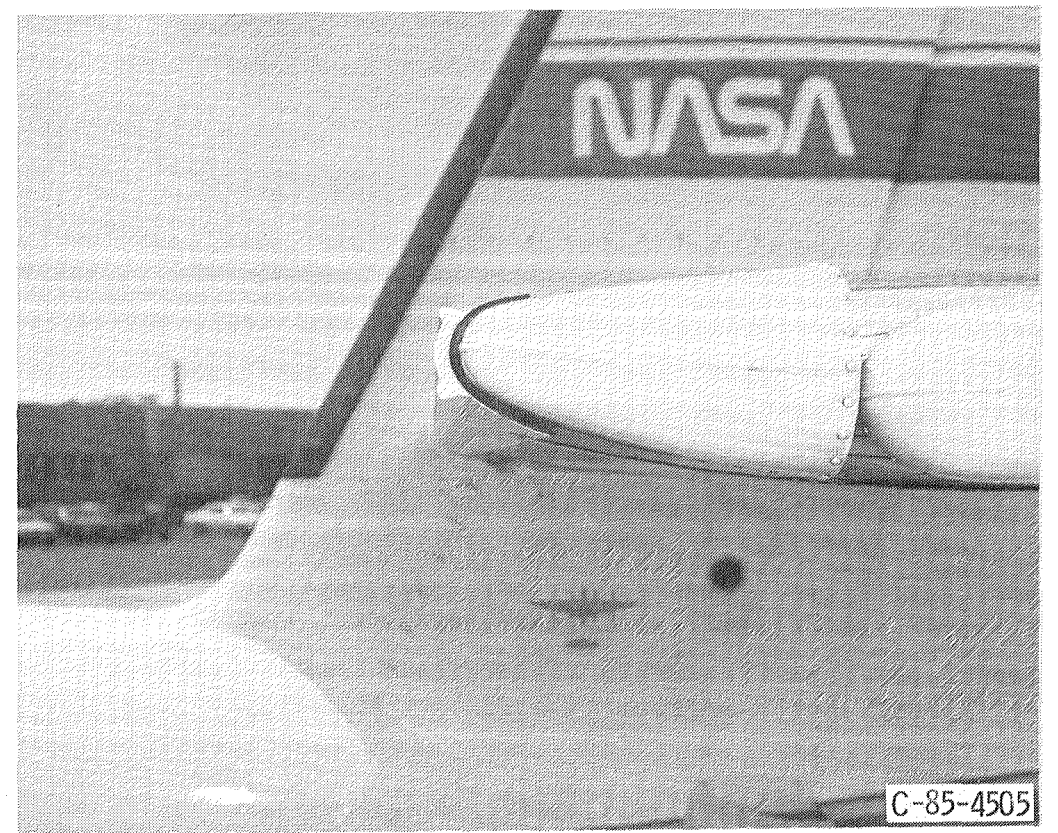

(b) Artificial "Light Glaze" ice shape.

Figure 6. - Artificial ice shapes attached to the horizontal tail plane. 


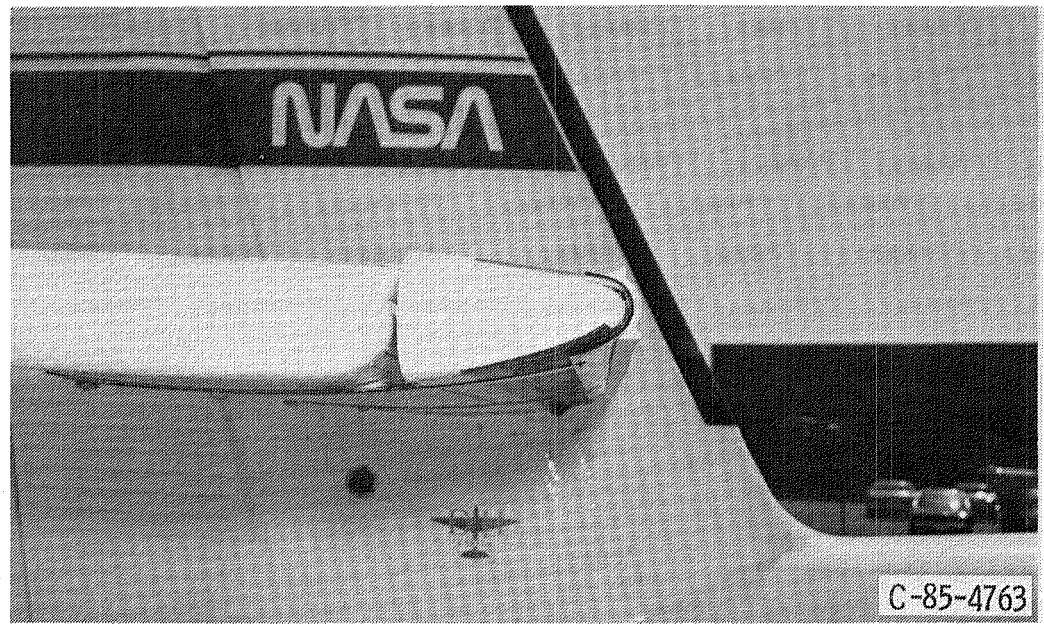

(c) Artificial "Moderate Glaze" ice shape.

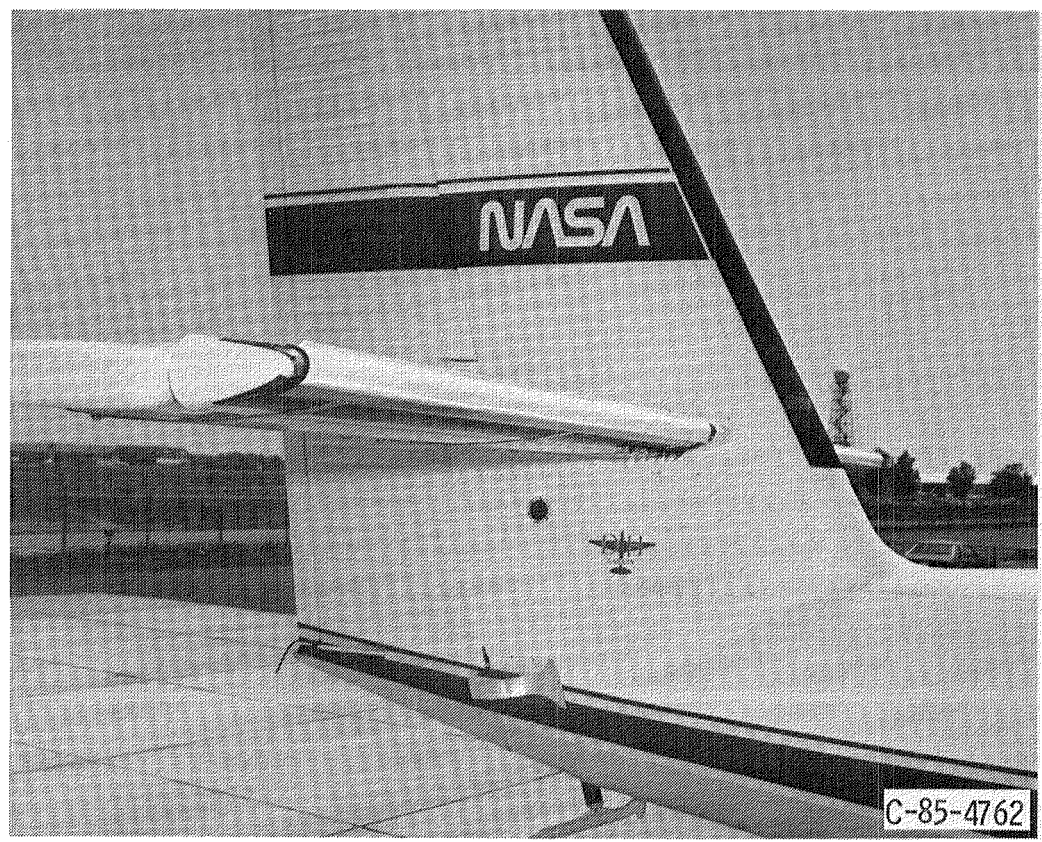

(d) Full span view of the moderate glaze ice shape.

Figure 6. - Concluded. 


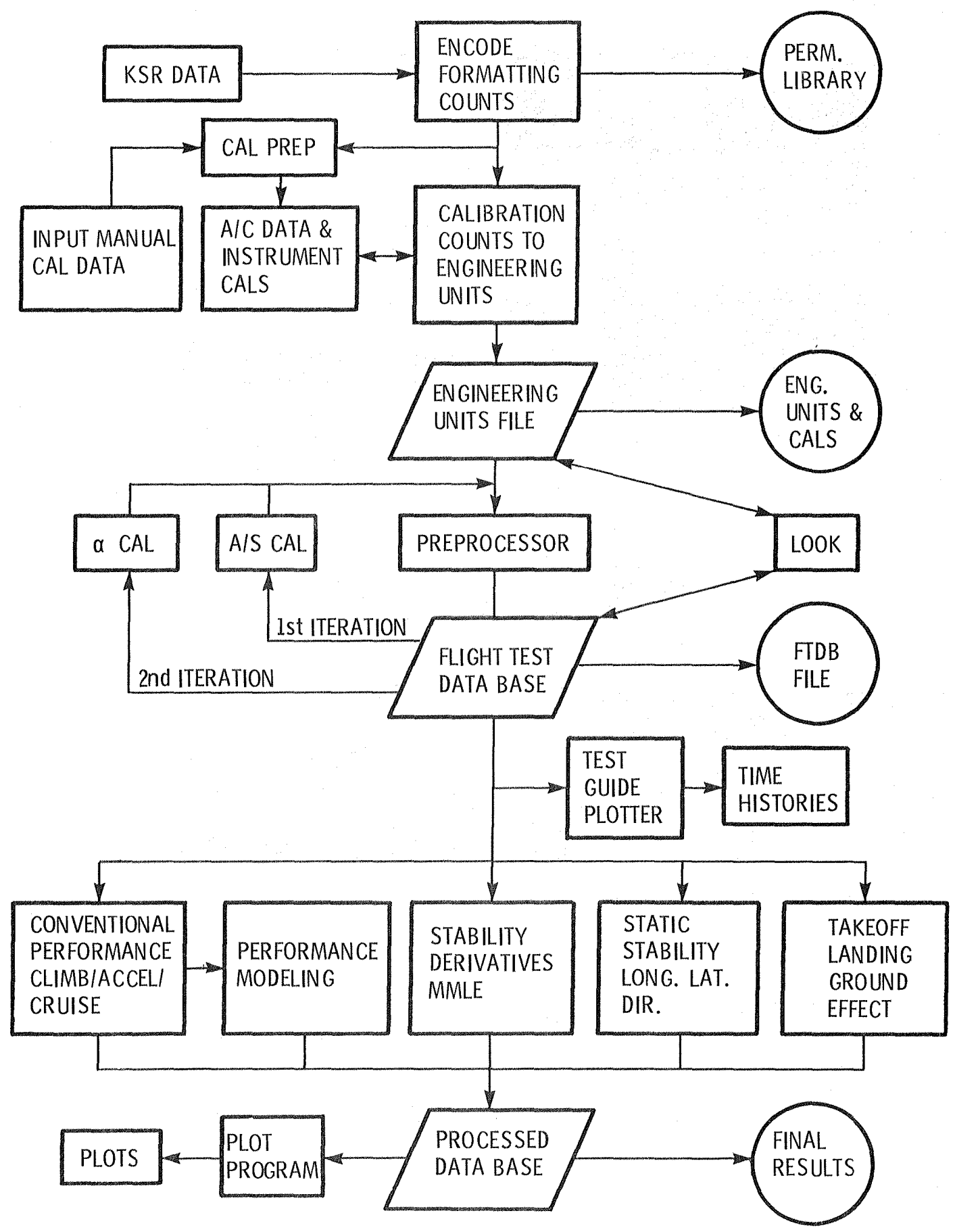

Figure 7. - KSR data management system. 


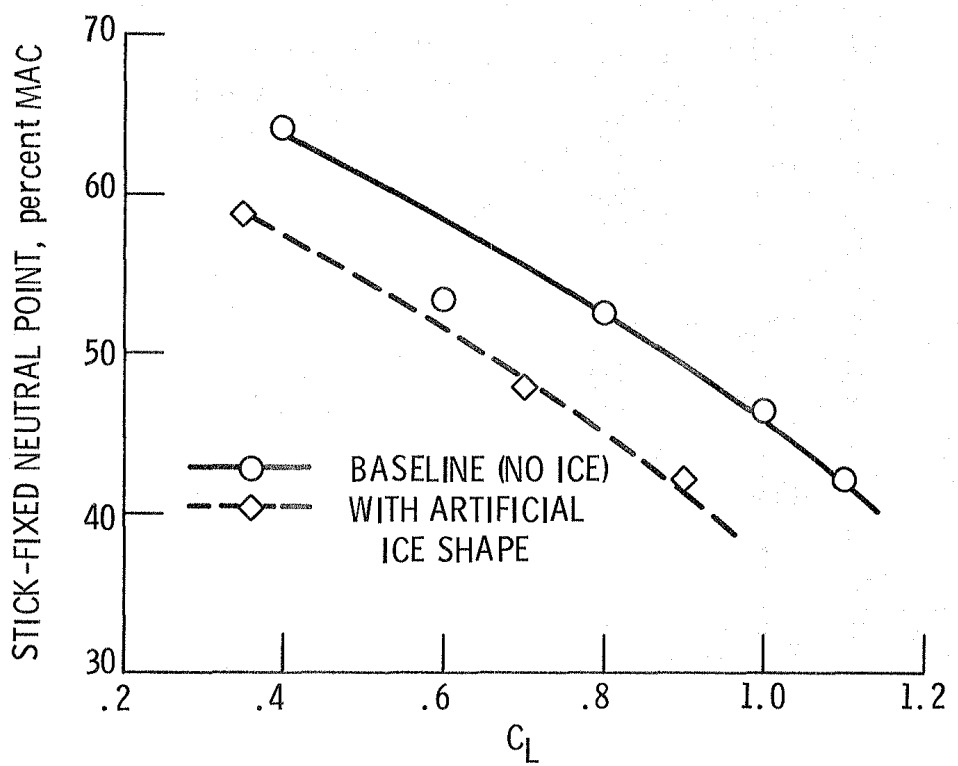

Figure 8. - Change in stick-fixed neutral points with artificial ice on horizontal tail. Nominal cruise power, 275 SHP per engine.

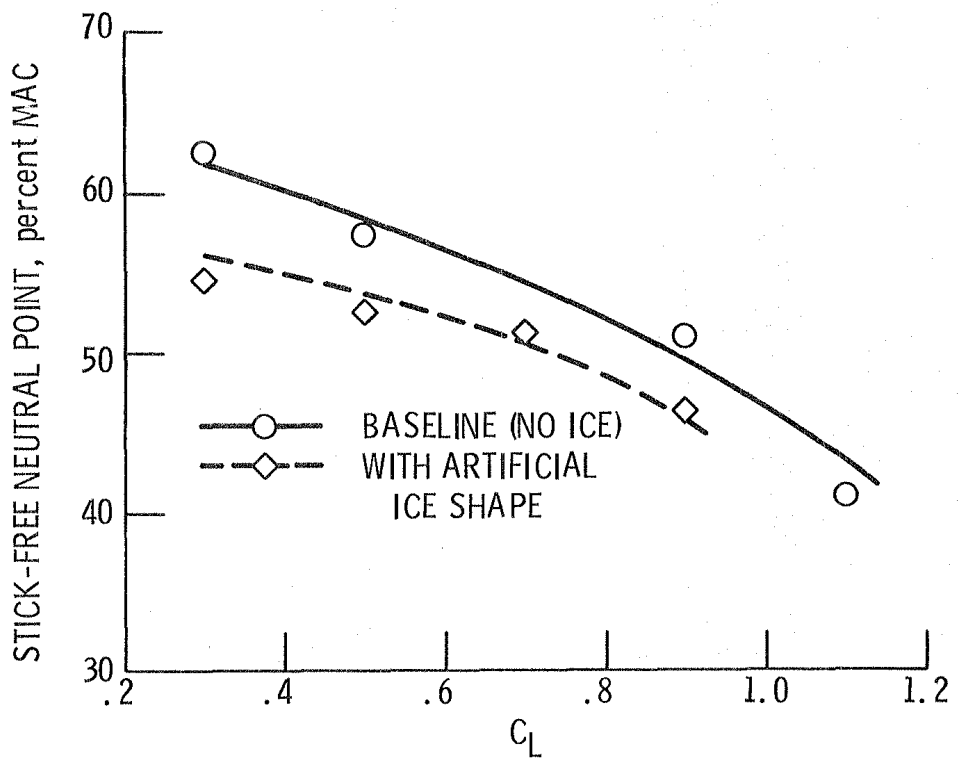

Figure 9. - Change in stick-free neutral points with artificial ice on horizontal tail. Nominal cruise power, 275 SHP per engine. 


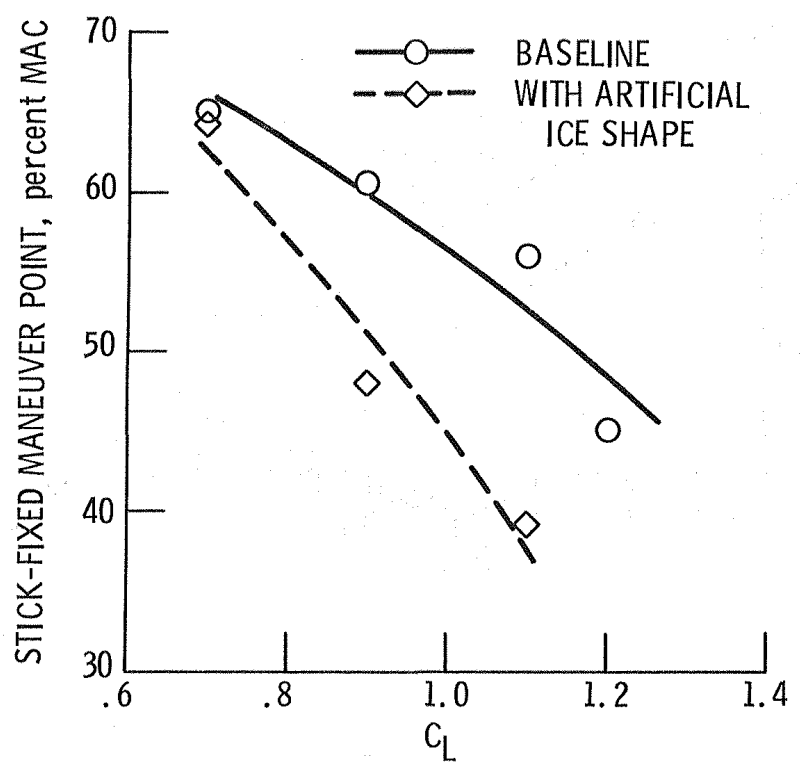

Figure 10. - Change in stick-fixed maneuver points with artificial ice on horizontal tail. Nominal cruise power, 275 SHP per engine. $V_{C A L}=103$ knots.

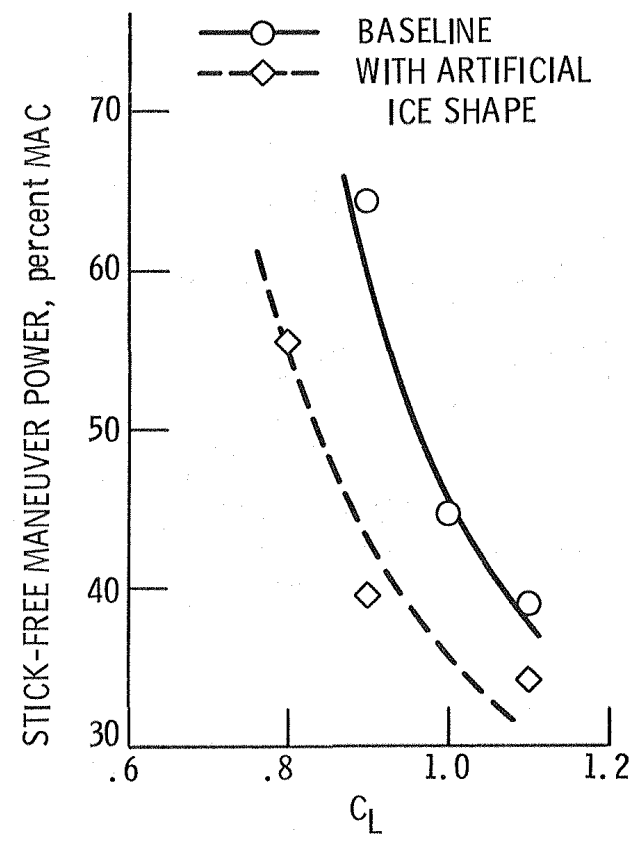

Figure 11. - Change in stick-free maneuver points with artificial ice on horizontal tail. Nominal cruise power, 275 SHP per engine. $V_{C A L}=103$ knots. 


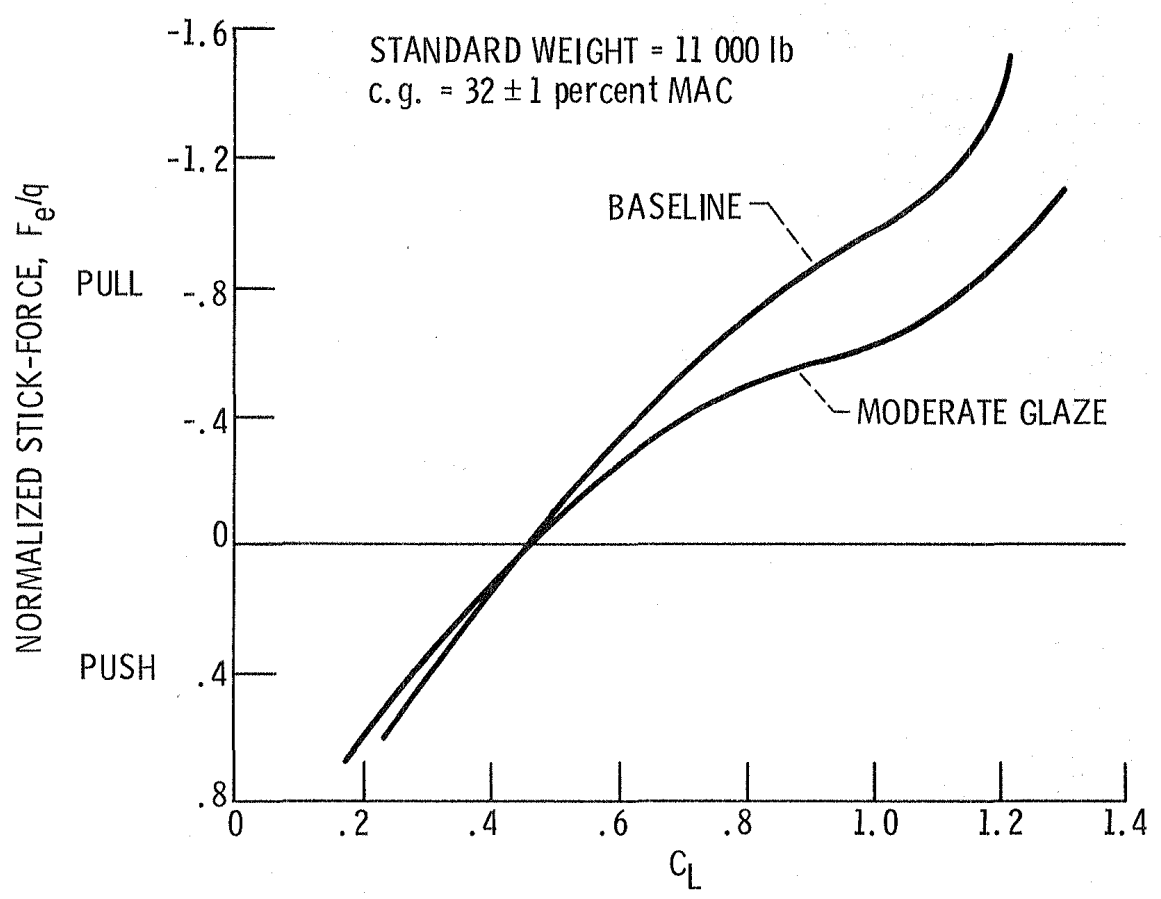

Figure 12. - Normalized longitudinal control force variation with lift coefficient for the clean horizontal tail versus the moderate glaze ice shape attached to the horizontal tail $\left(\delta_{F}=0^{0}\right)$. 

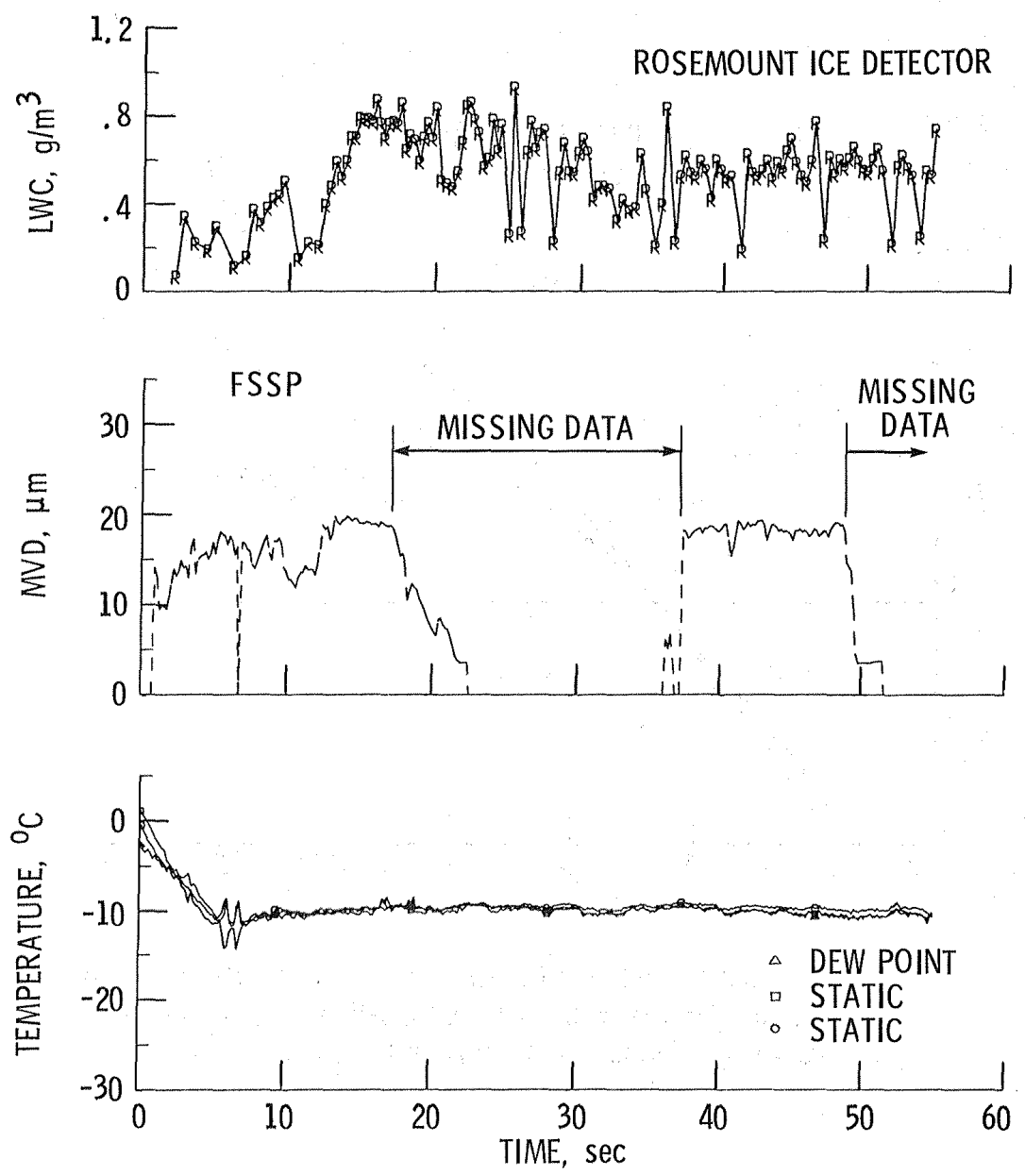

Figure 13. - Icing data for performance flight 86-20. 

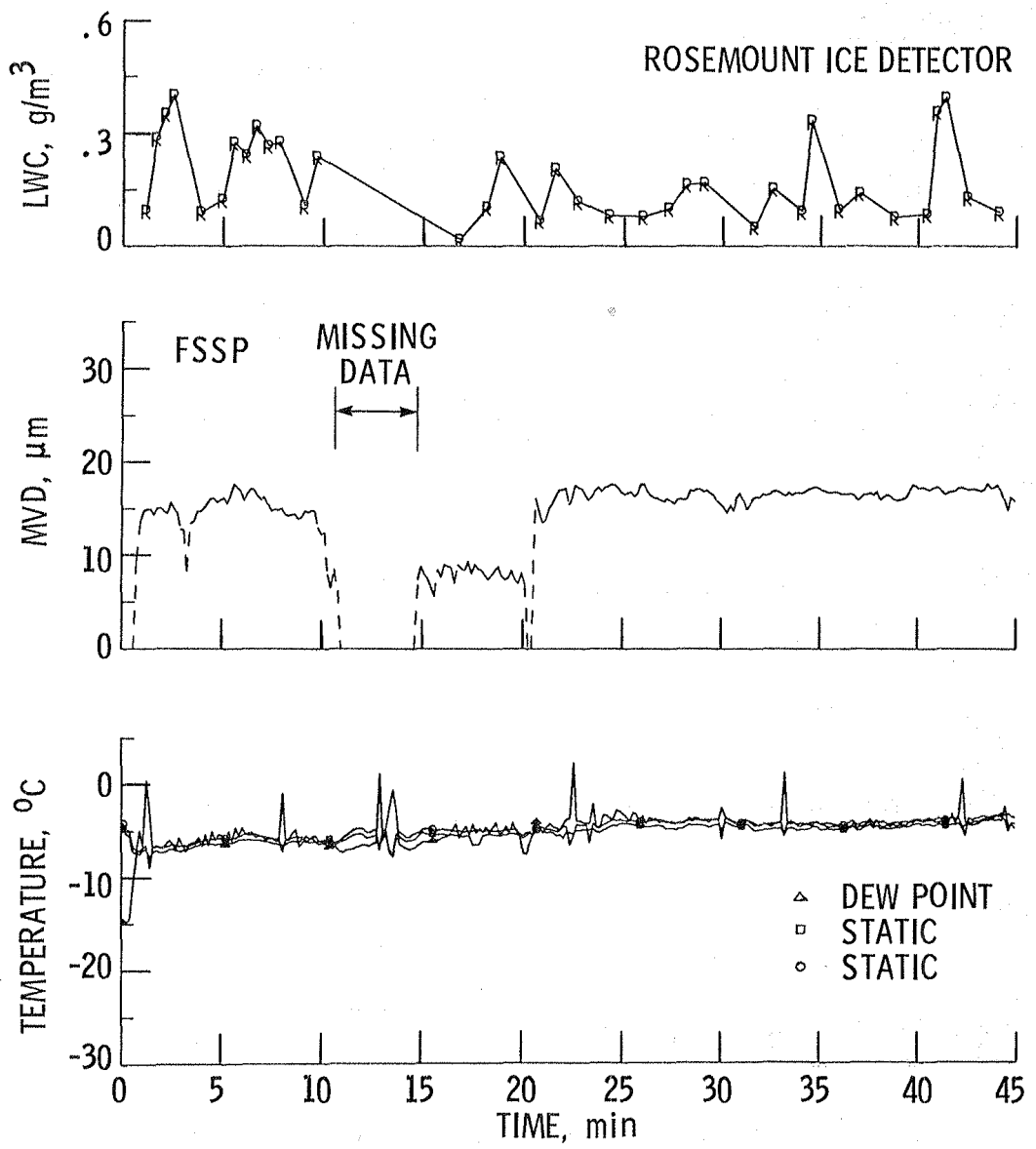

Figure 14. - Icing data for performance flight 86-21. 

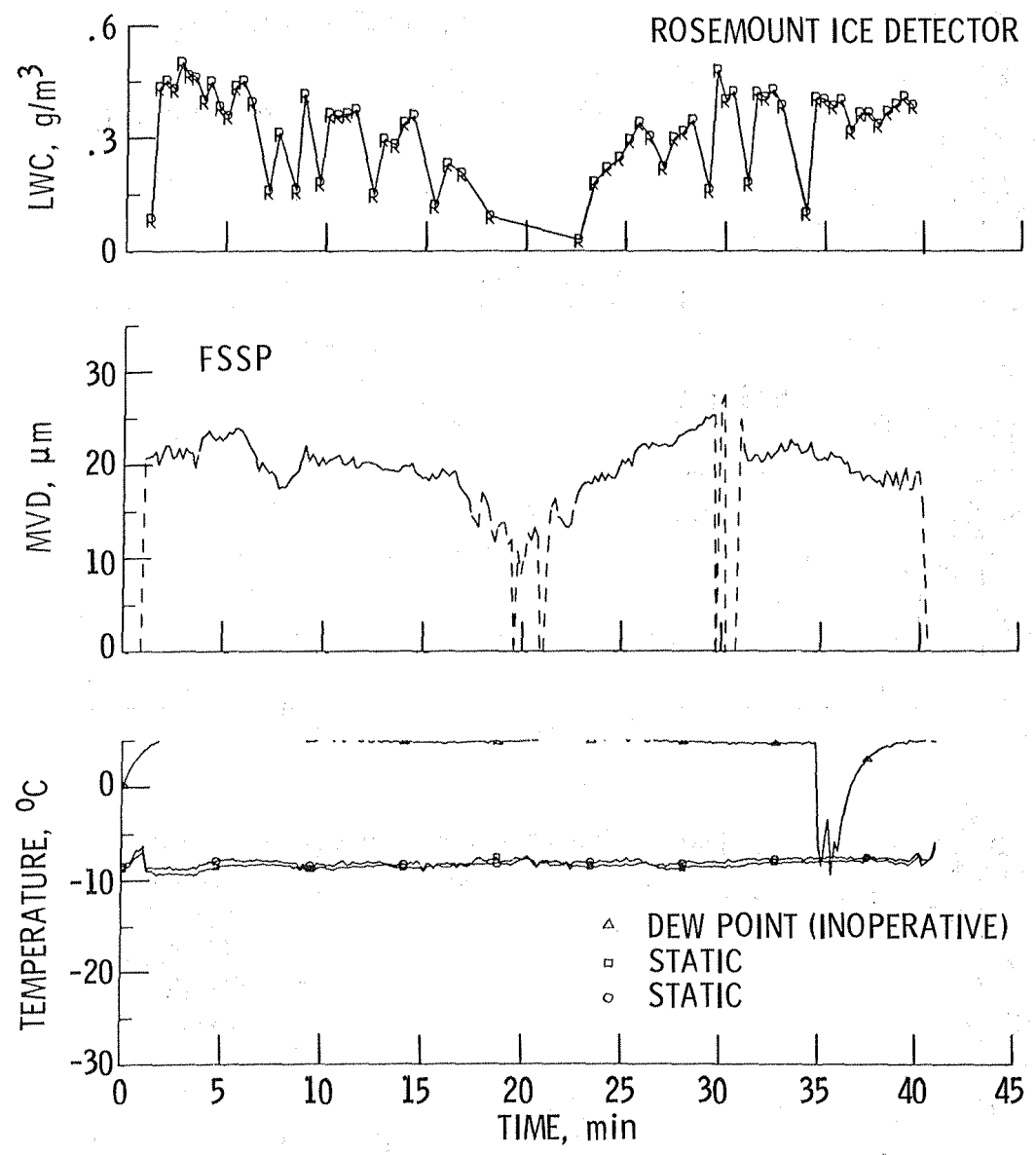

Figure 15. - Icing data for stability and control flight 86-16. 

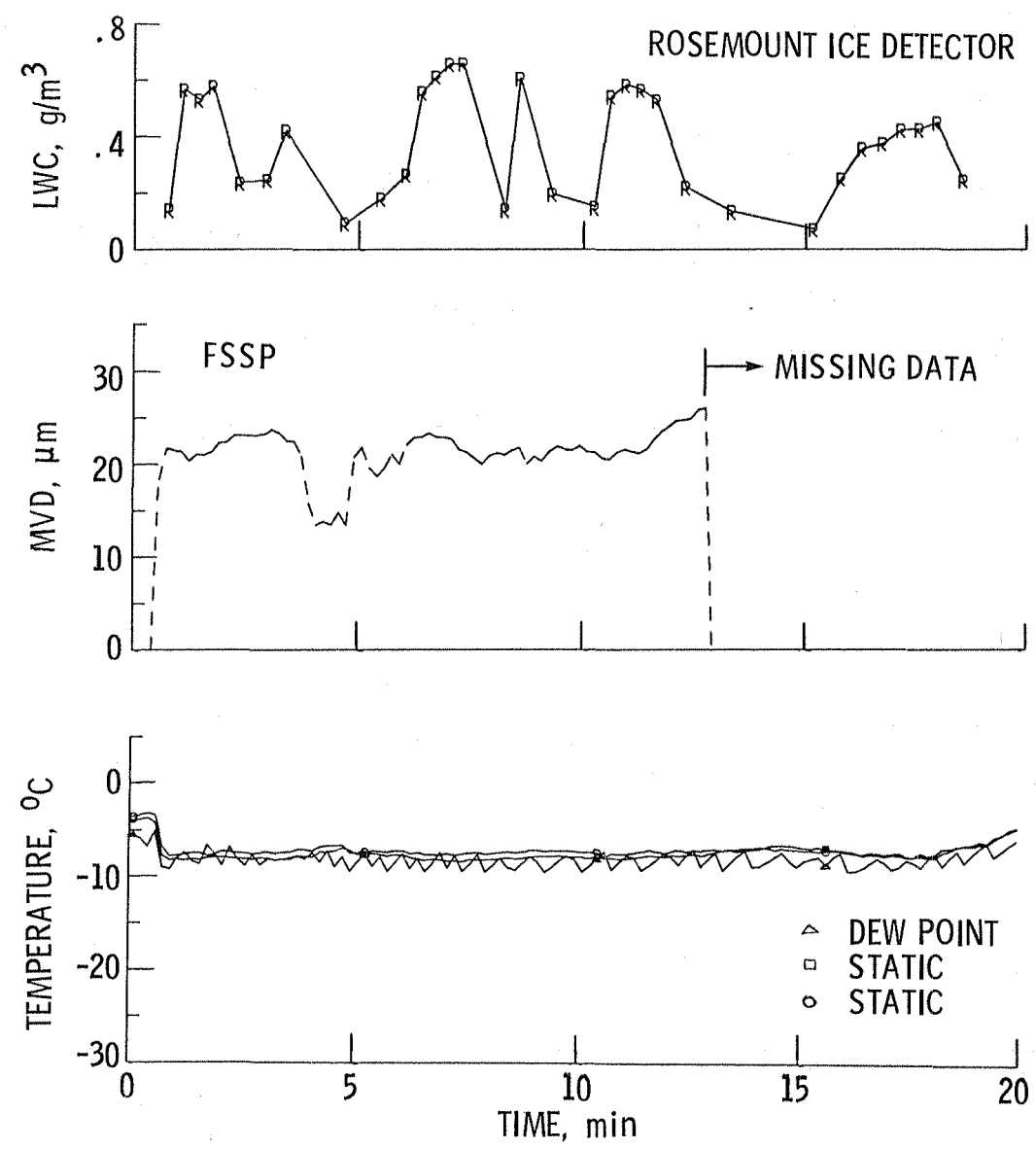

Figure 16. - Icing data for stability and control flight 86-17. 

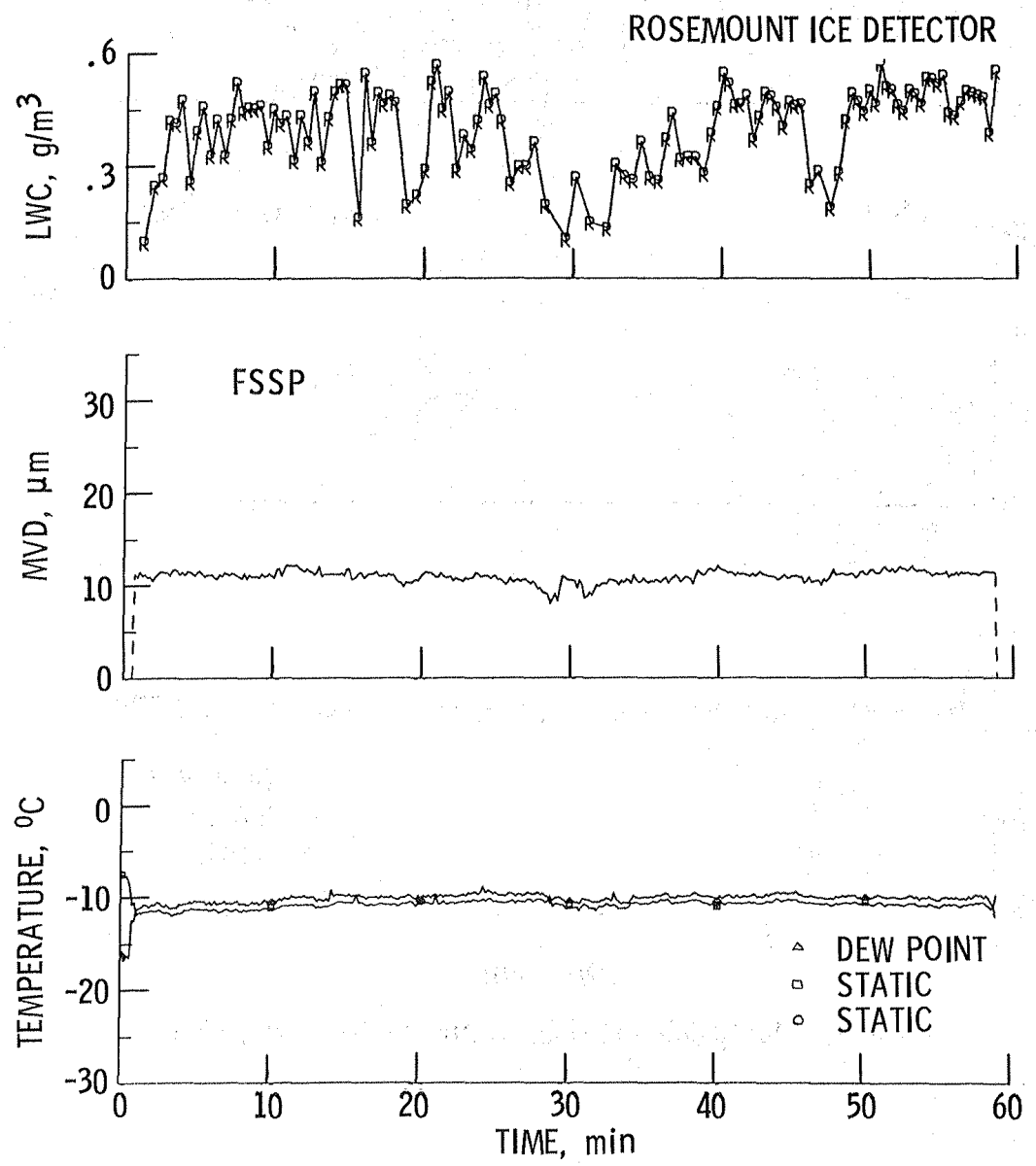

Figure 17. - Icing data for stability and control flight 86-23. 


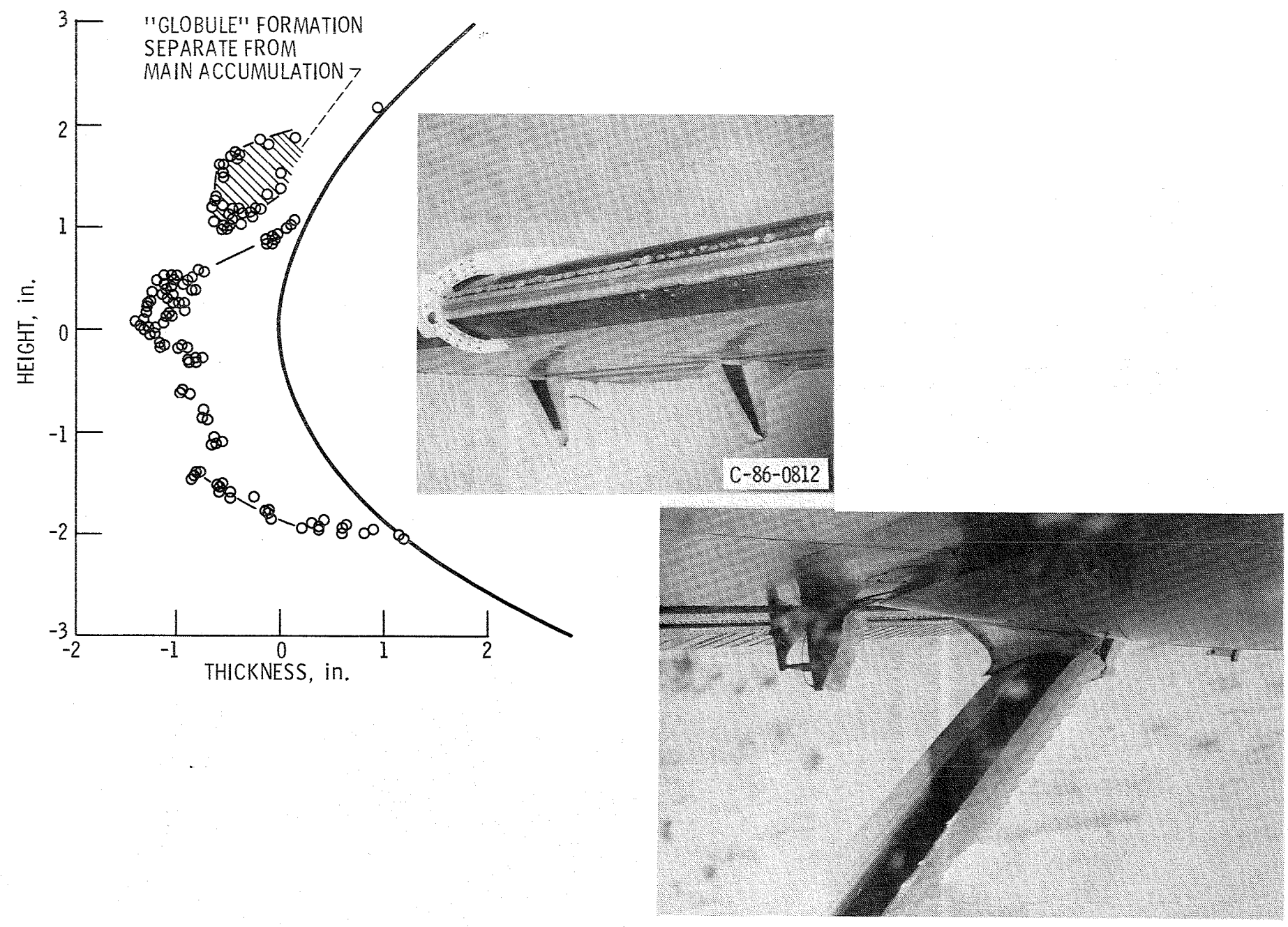

Figure 18. - Wing stereo analysis and photograph of wing strut for performance flight 86-20 for moderate to heavy mixed icing conditions. 


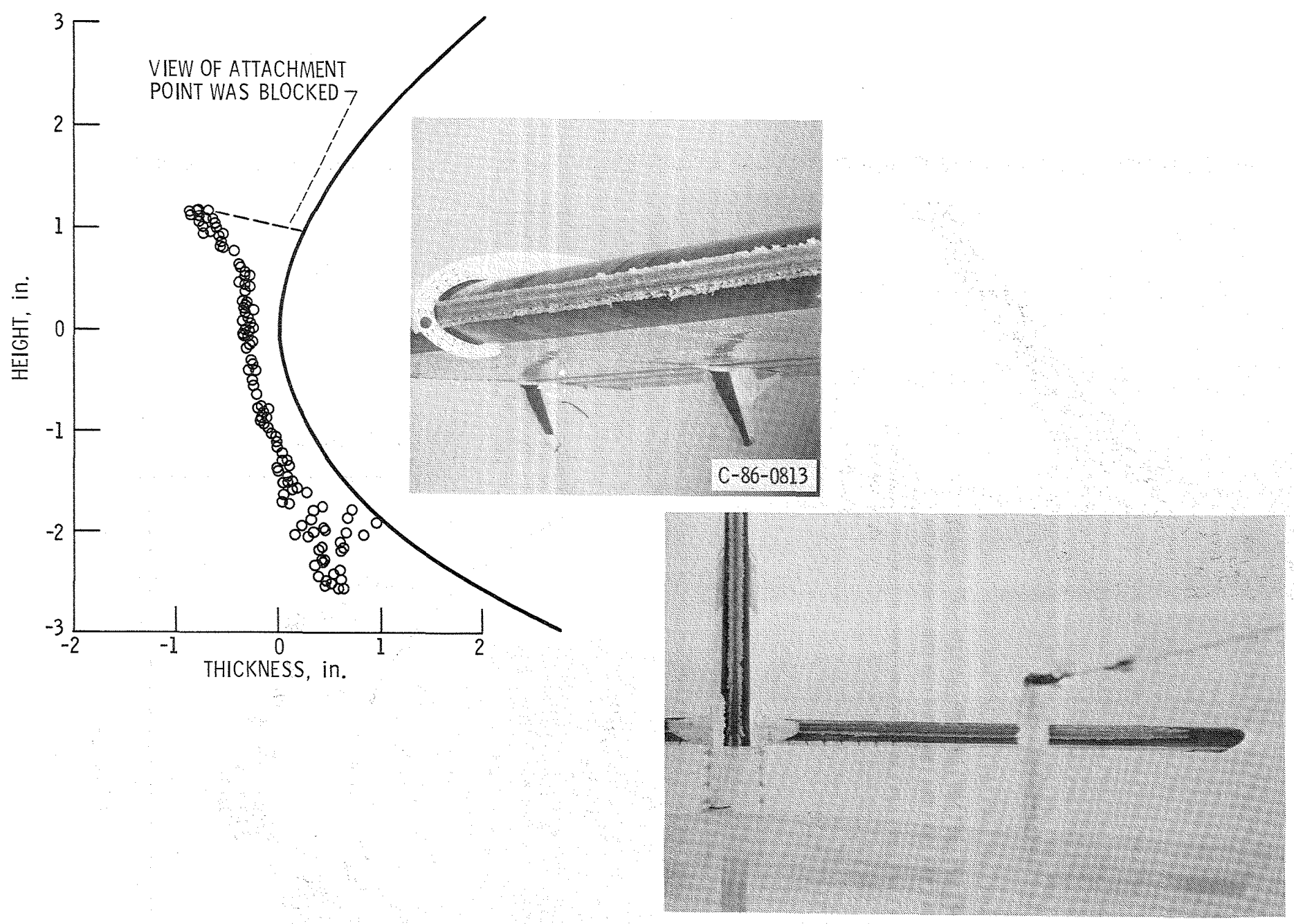

Figure 19. - Wing stereo analysis and photograph of empennage for performance flight $86-21$ for moderate glaze icing conditions. 


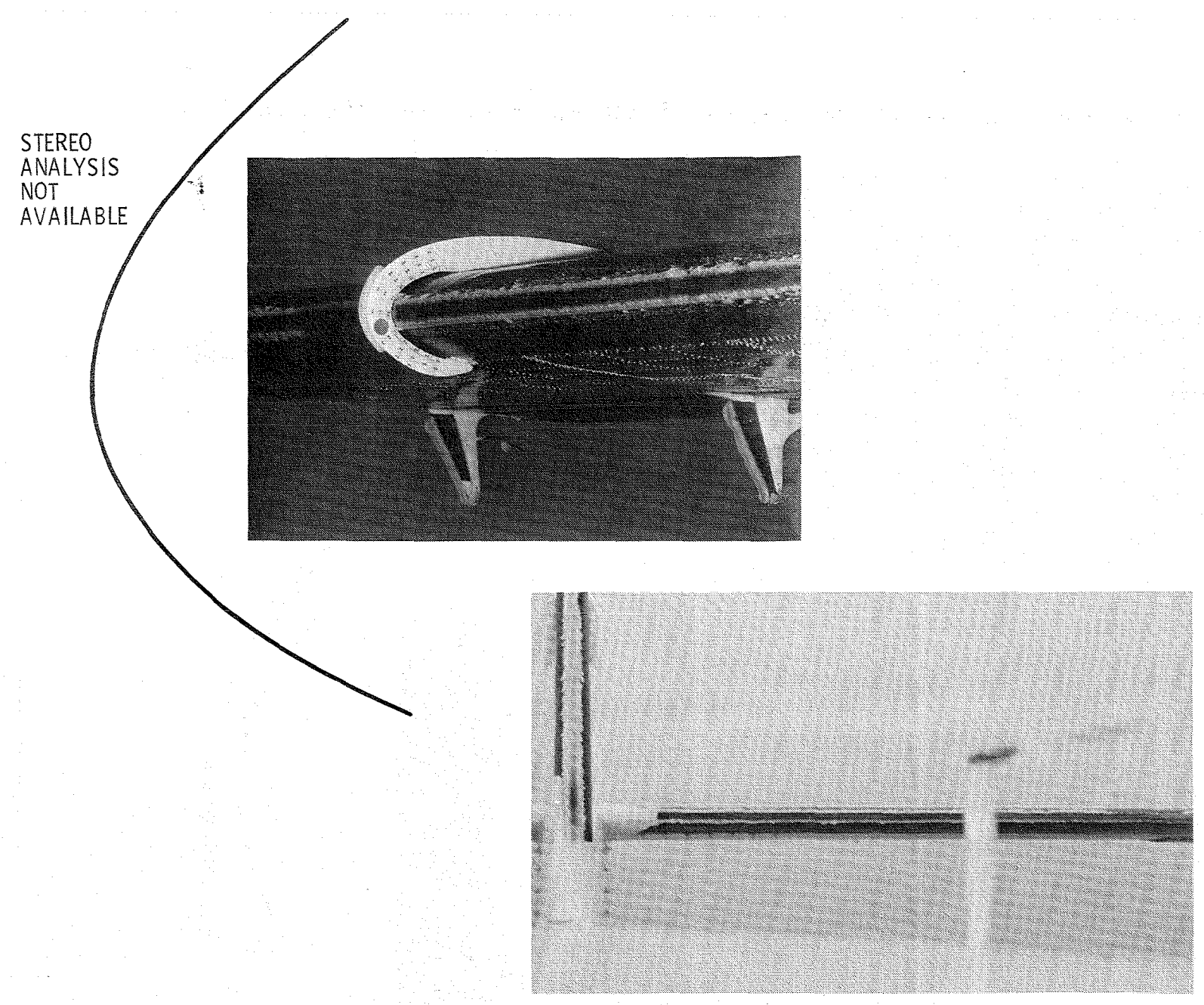

Figure 20. - Wing ice shape and empennage photographs for stability and control flight 86-16 for mixed icing conditions. 


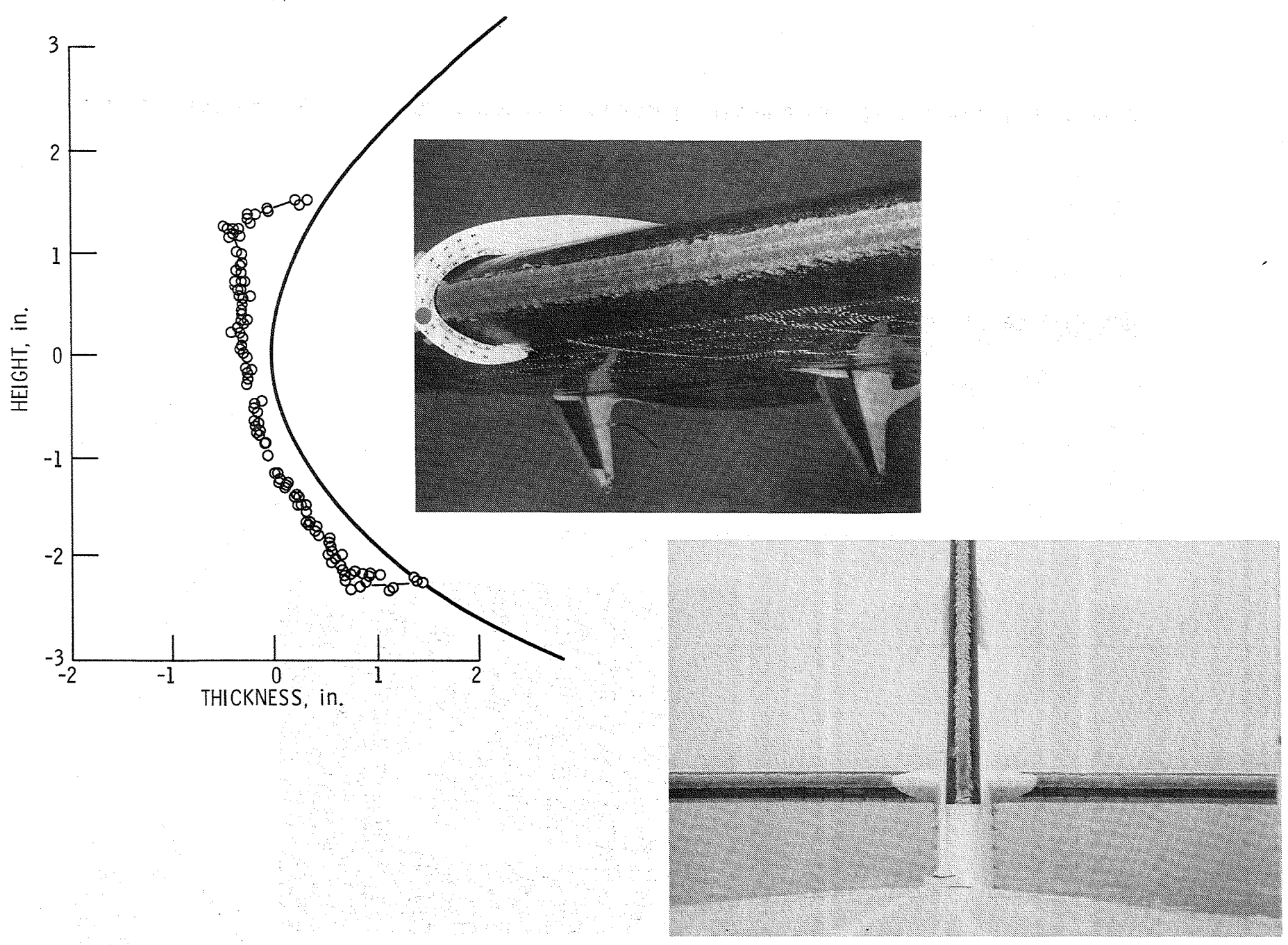

Figure 21. - Wing stereo analysis and photograph of empennage for stability and control flight 86-17 for mixed icing conditions. 


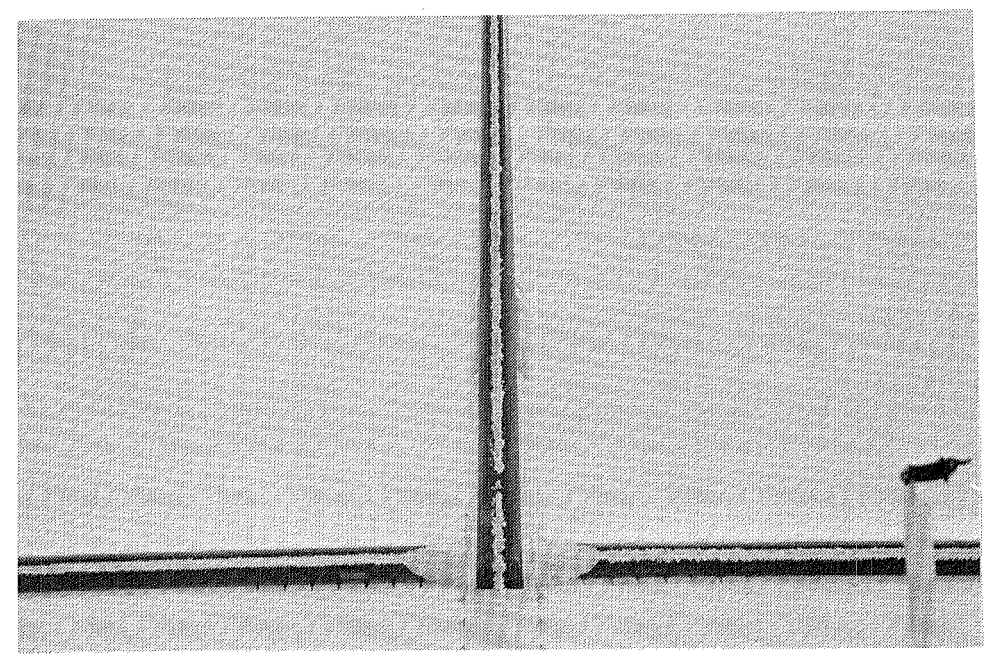

Figure 22. - Rime ice on empennage during flight 86-23. 

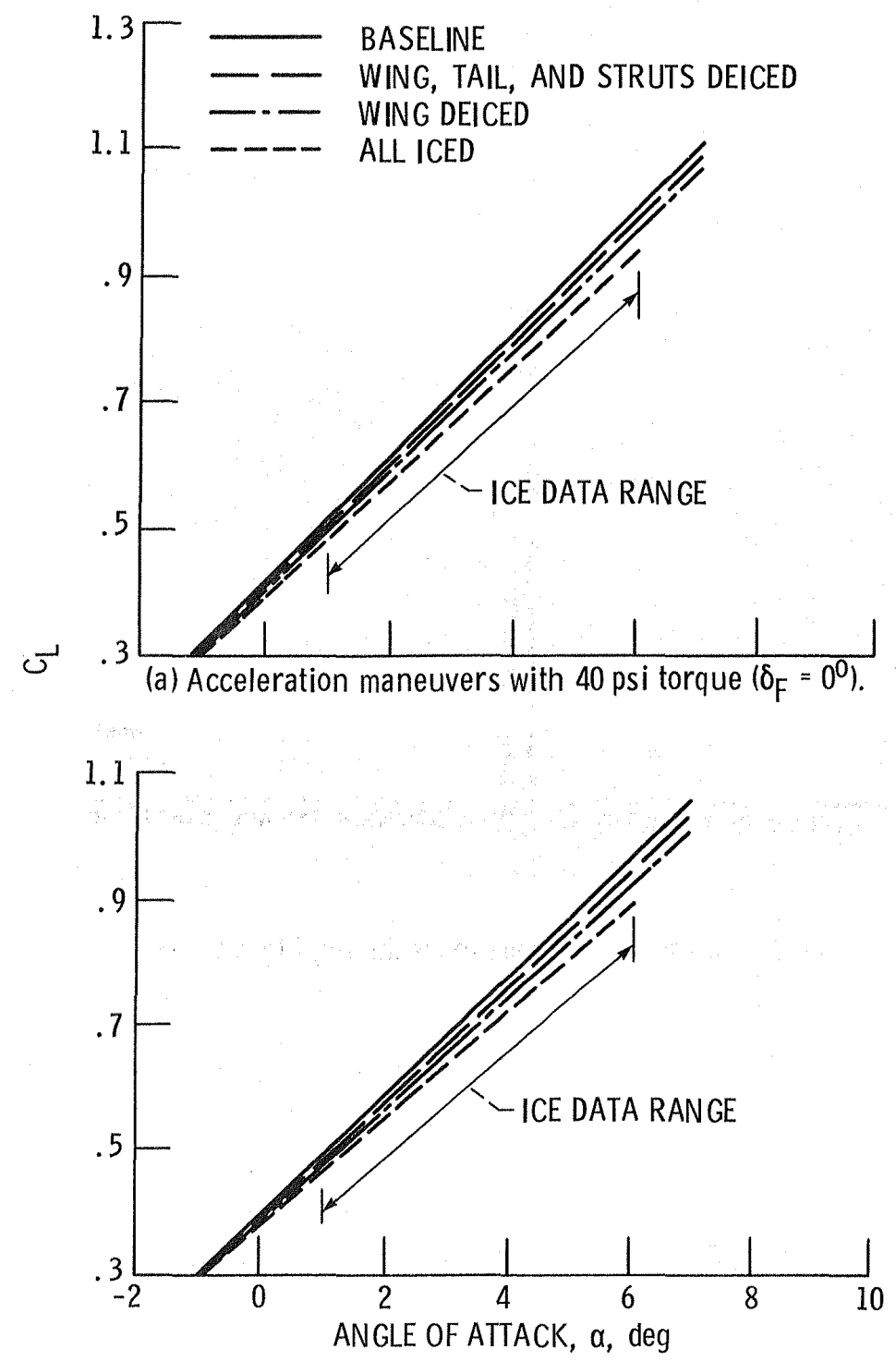

(b) Deceleration maneuvers with 15 psi torque $\left(\delta_{\mathrm{F}}=0^{0}\right)$.

Figure 23. - Effect of mixed ice on lift curve for performance flight 86-20. 


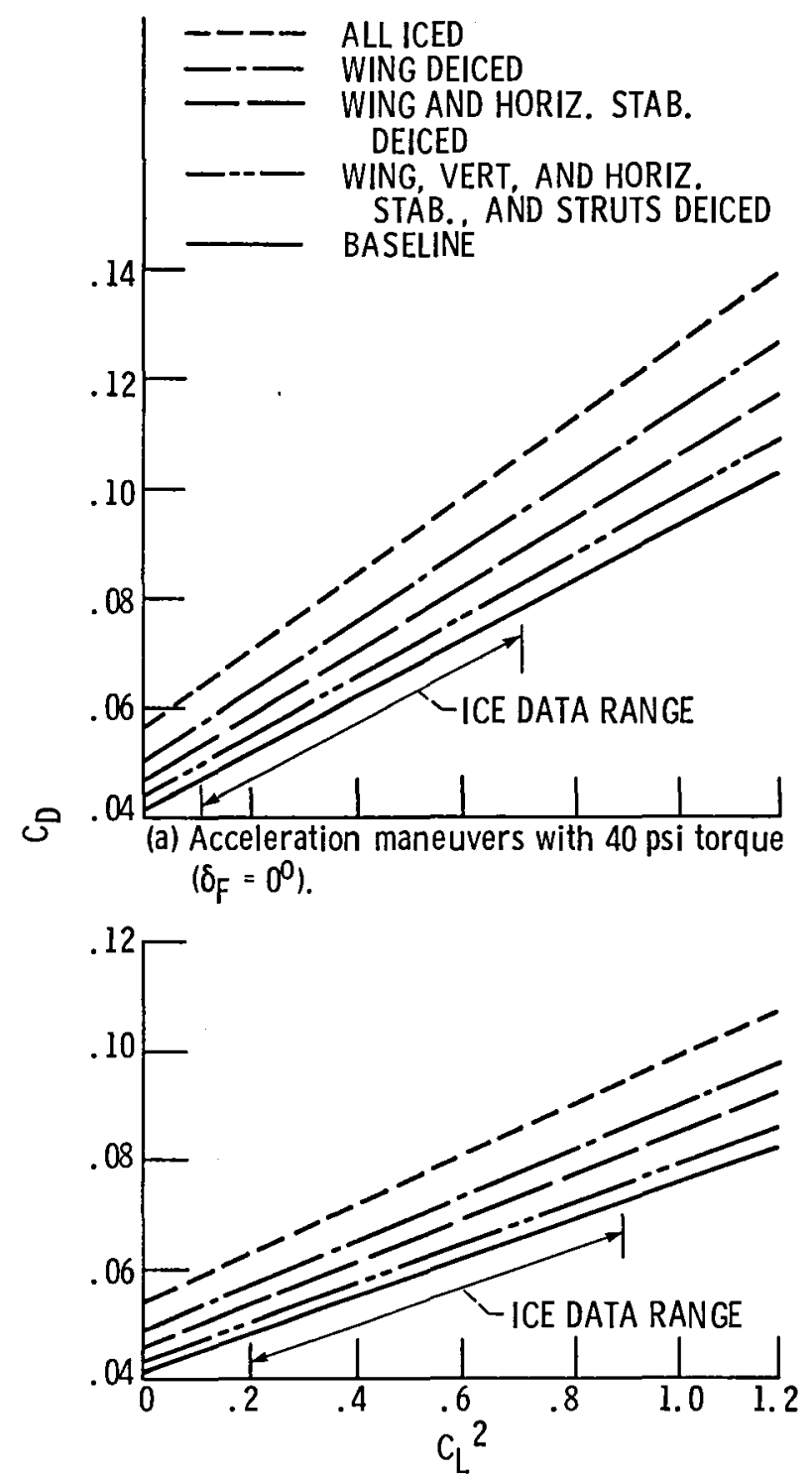

(b) Deceleration maneuvers with 15 psi torque $\left(\delta_{F}=0 \%\right)$.

Figure 24. - Effect of mixed ice on aircraft drag for performance flight 86-20. 

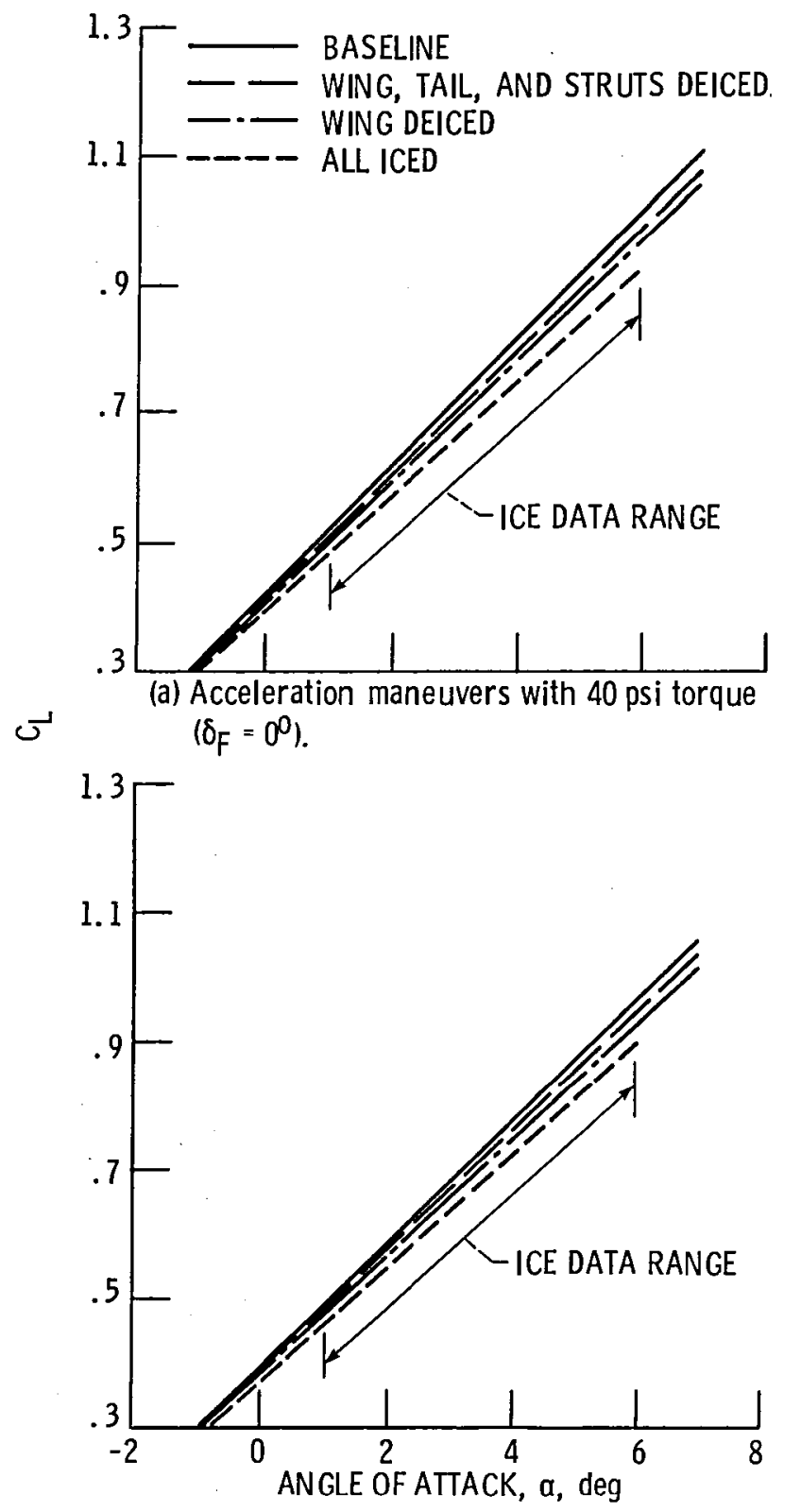

(b) Deceleration maneuvers with 15 psi torque $\left(\delta_{F}=0^{0}\right)$.

Figure 25. - Effect of glaze ice on lift curve for performance flight 86-21. 


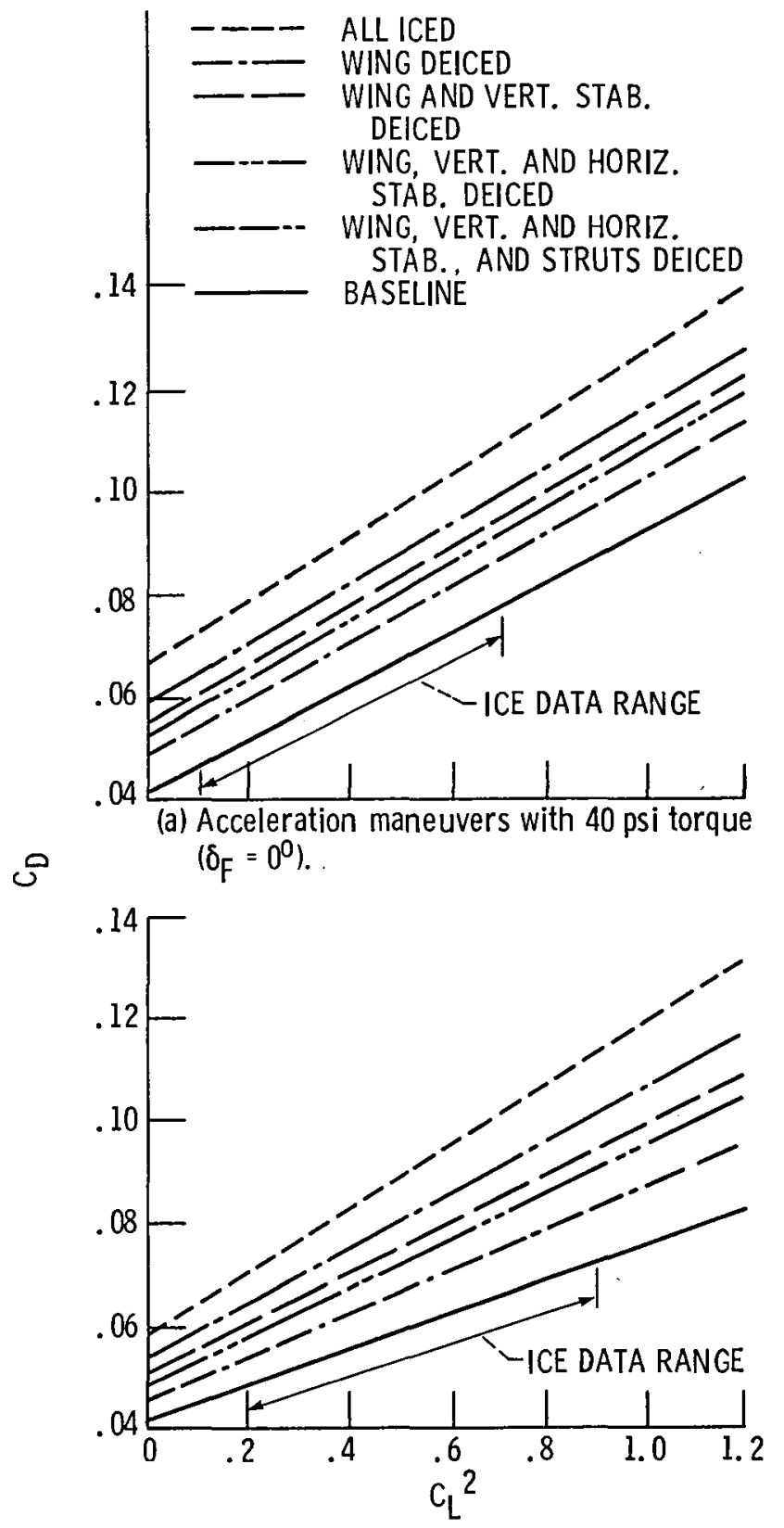

(b) Deceleration maneuvers with 15 psi torque $\left(\delta_{\mathrm{F}}=0^{\circ}\right)$.

Figure 26. - Effect of glaze ice on aircraft drag for performance flight 86-21. 


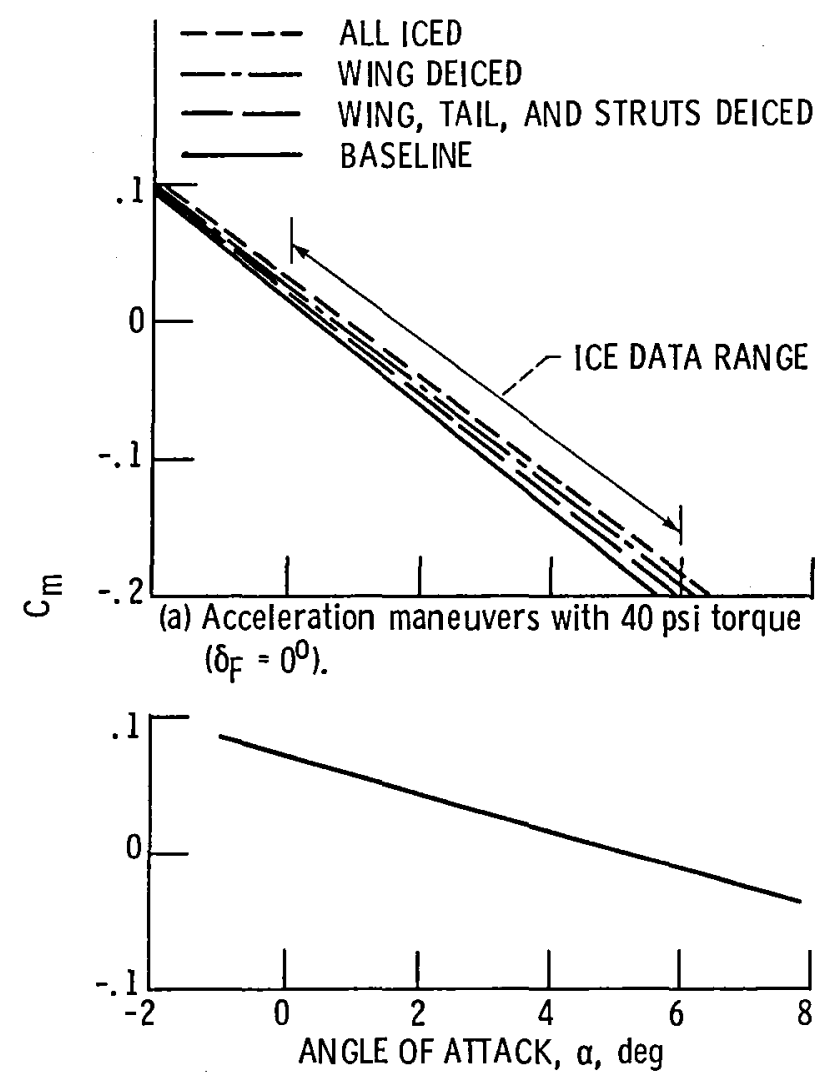

(b) Deceleration maneuvers with 15 psi torque $\left(\delta_{F}=0^{\circ}\right)$. Ice had no effect.

Figure 27. - Effect of ice on $C_{m}$ versus $a$. Results were the same for performance 86-20 and 21. 


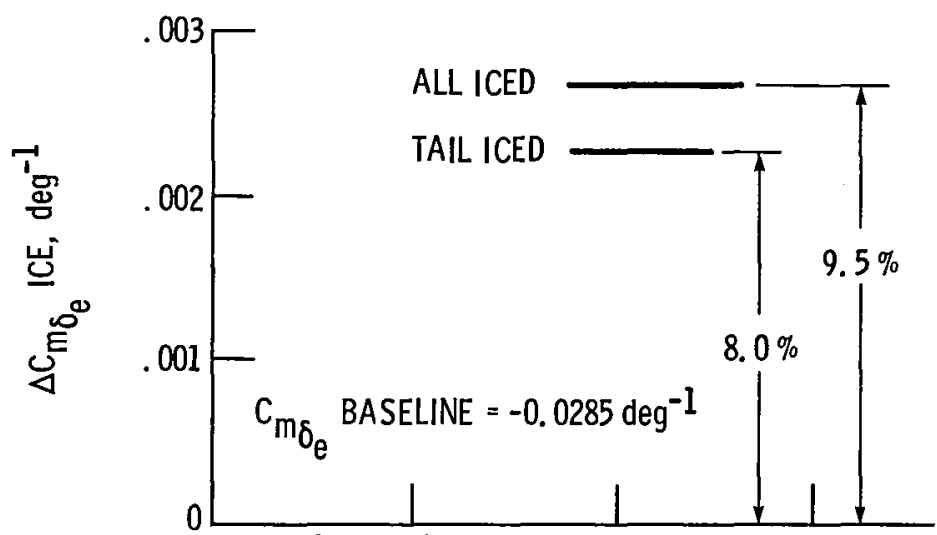

(a) Degradation in elevator power derivative.

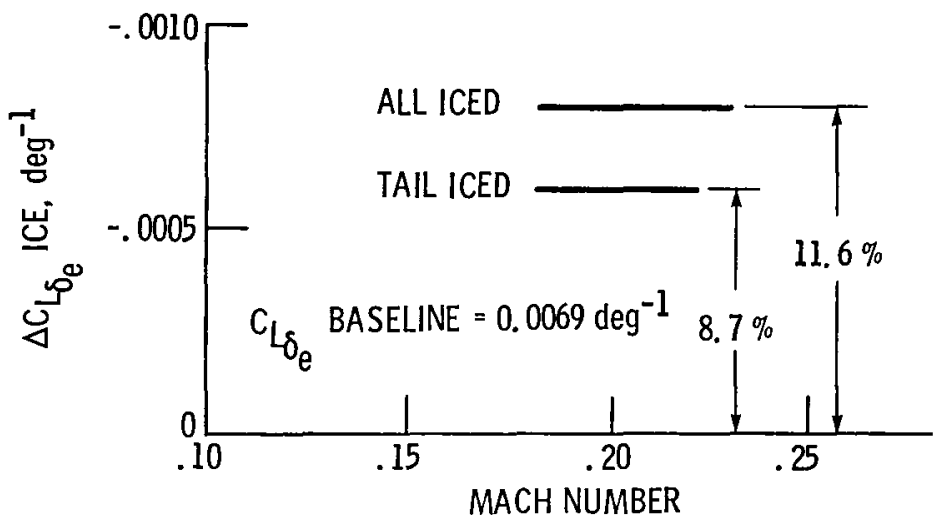

(b) Degradation in elevator effectiveness derivative.

Figure 28. - Effect of mixed icing conditions on the elevator derivatives for stability and control flight $86-16\left(\delta_{F}=0^{\circ}\right.$ and $C_{T}=0.06$ to 0.08$)$. 


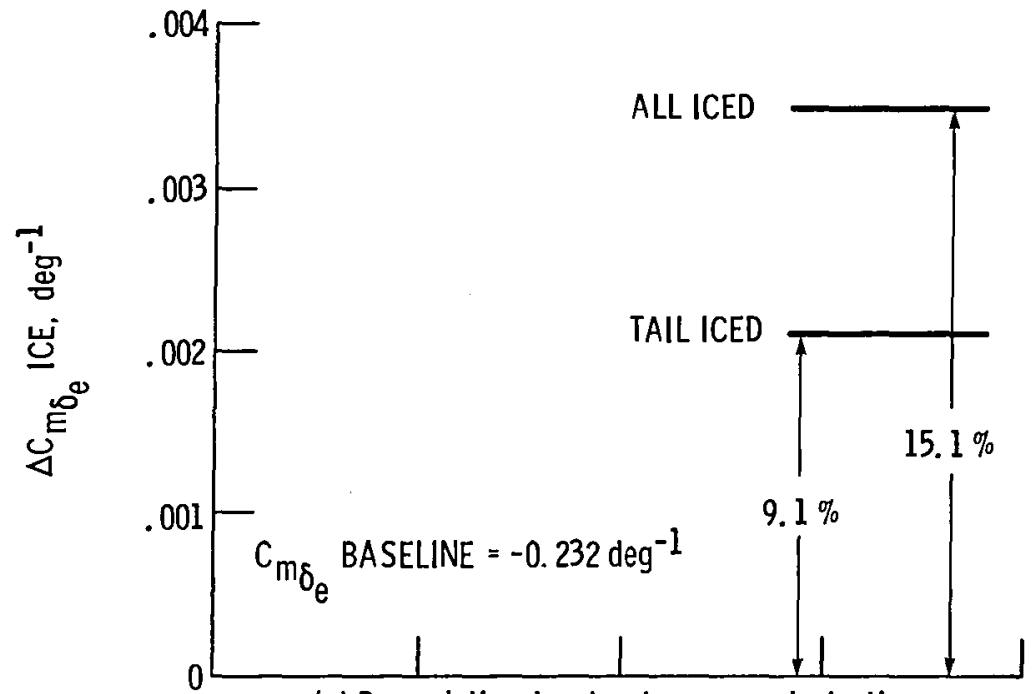

(a) Degradation in elevator power derivative.

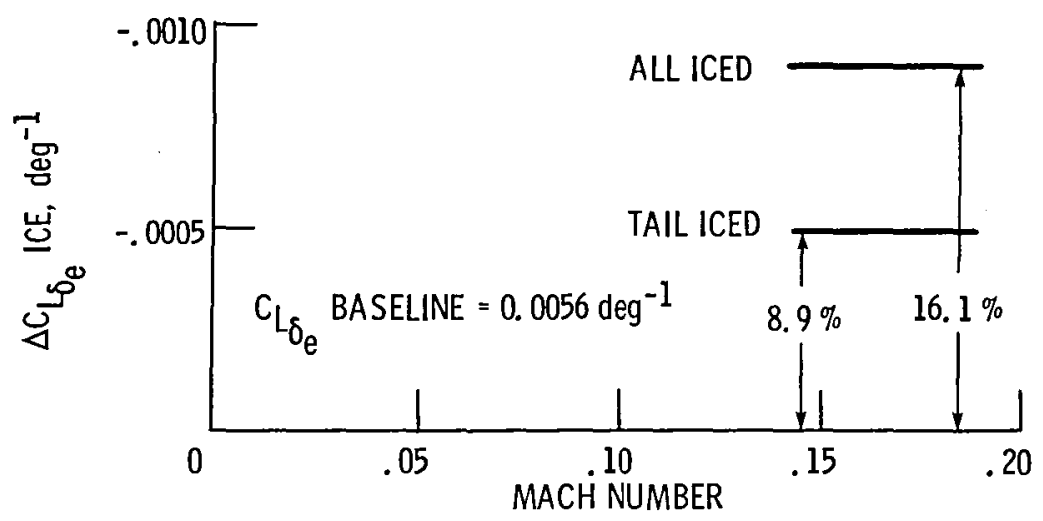

(b) Degradation in elevator effectiveness derivative.

Figure 29. - Effect of mixed icing conditions on the elevator derivatives for stability and control flight $86-16 \quad 1 \delta_{F}=10^{\circ}$ and $C_{T}=0.05$ to 0.07 ). 


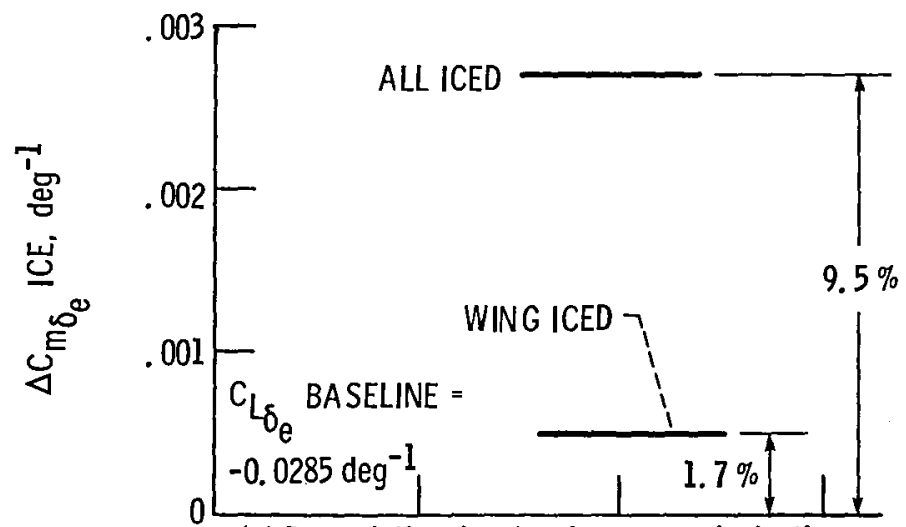

(a) Degradation in elevator power derivative.

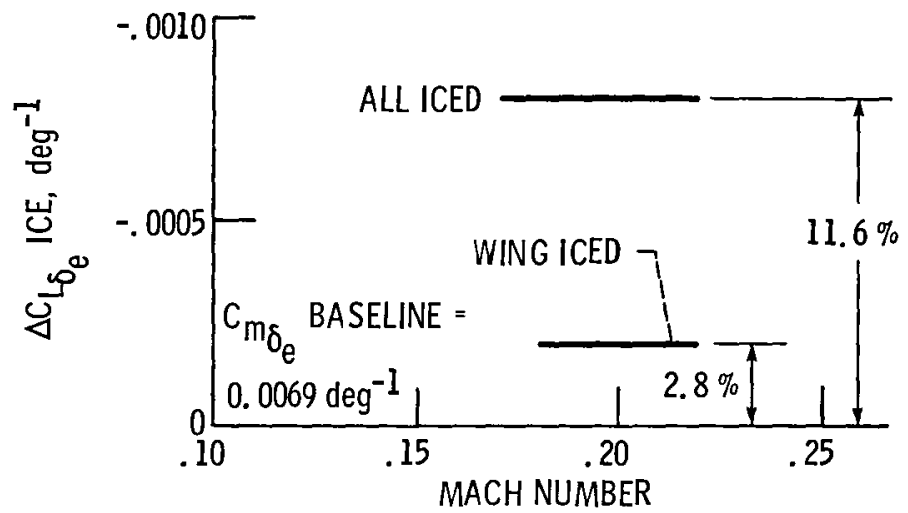

(b) Degradation in elevator effectiveness derivative.

Figure 30. - Effect of mixed icing conditions on the elevator derivatives for stability and control flight $86-17\left(\delta_{F}=0^{0}\right.$ and $C_{T}=0.06$ to 0.08$)$. 


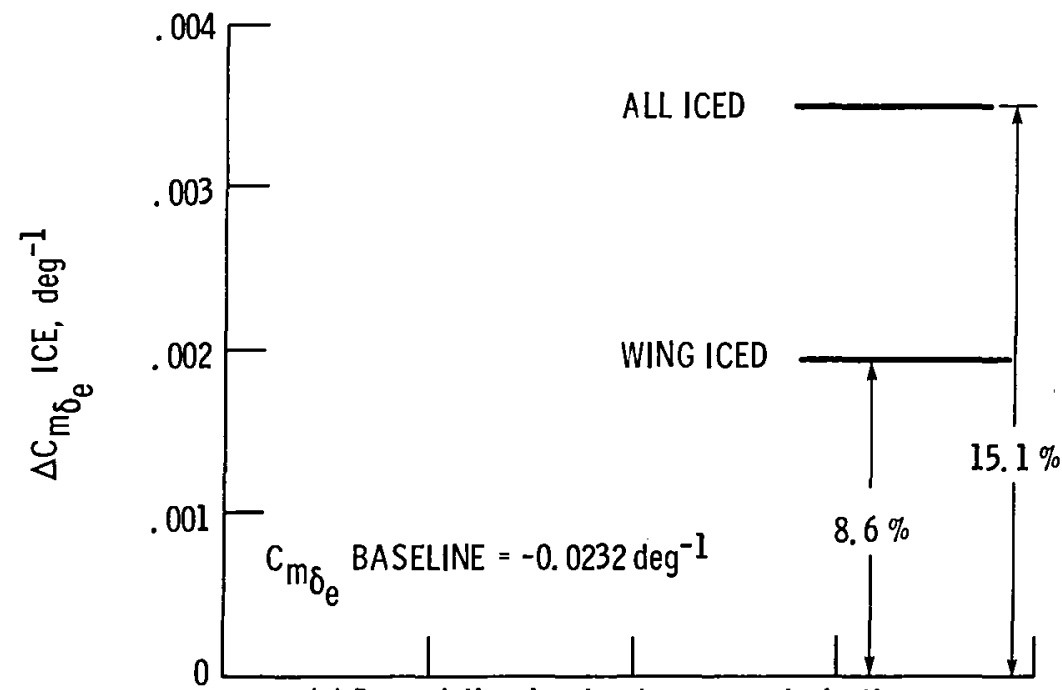

(a) Degradation in elevator power derivative.

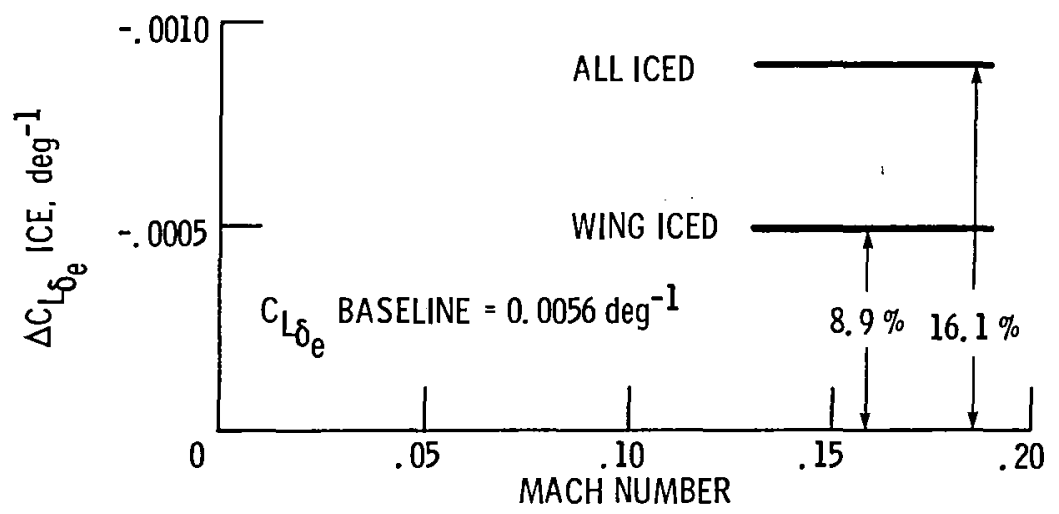

(b) Degradation in elevator effectiveness derivative.

Figure 31. - Effect of mixed icing conditions on the elevator derivatives for stability and control flight $86-17\left(\delta_{F}=10^{\circ}\right.$ and $C_{T}=0.05$ to 0.07 ). 


$$
\begin{gathered}
\left(c_{m_{\mathrm{q}}}+c_{m_{\dot{\alpha}}}\right) \text { BASELINE }=-48 \mathrm{rad}^{-1} \\
\delta_{F}=0^{0} \\
\Delta\left(c_{m_{q}}+c_{m_{\dot{\alpha}}}\right) \text { ICE }=0
\end{gathered}
$$

(a) Degradation in pitch damping coefficient was indiscernable at $\delta_{F}=0^{\circ}$ and $C_{T}=0.06$ to 0.08 .

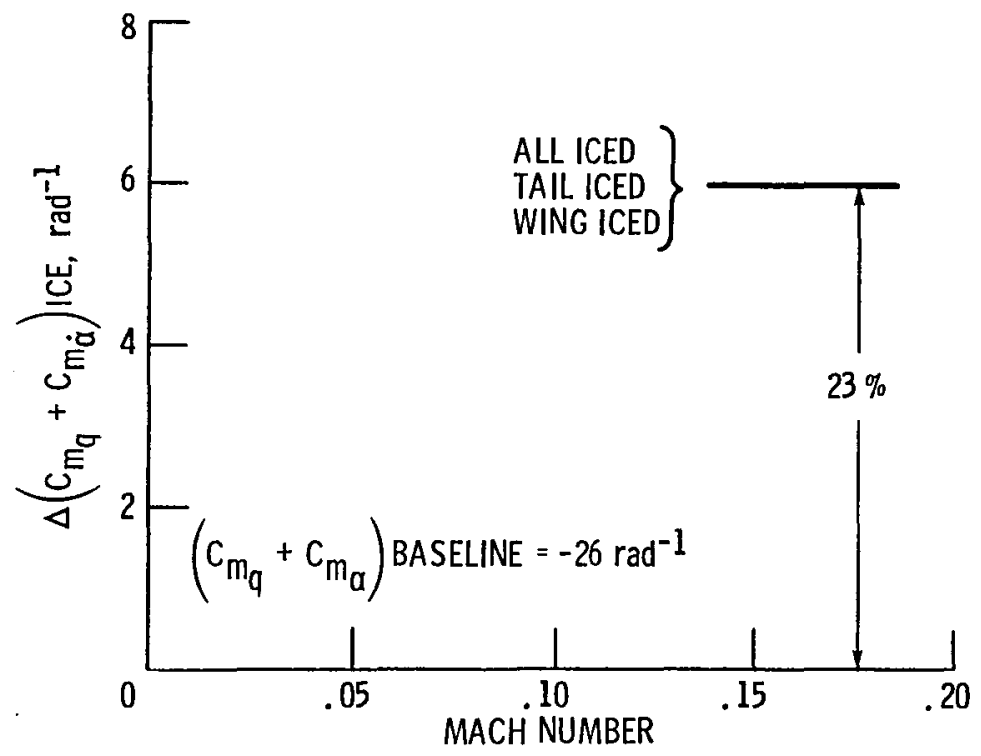

(b) Degradation in pitch damping state coefficient at $\delta_{F}=10^{\circ}$ and $C_{T}=0.05$ to 0.07 .

Figure 32. - Effect of mixed icing conditions on pitch damping state coefficient for flights 86-16 and 86-17. Note, results were the same for both flights. 


$$
\begin{gathered}
\left(C_{L_{q}}+C_{L_{\dot{\alpha}}}\right) \text { BASELINE }=10.8 \mathrm{rad}^{-1} \\
\delta_{F}=0^{0} \\
\Delta\left(C_{L_{q}}+C_{L_{\dot{\alpha}}}\right) \text { ICE }=0
\end{gathered}
$$

(a) Degradation in state coefficient was indiscernable at $\delta_{F}=0^{0}$ AND $C_{T}=0.06$ to 0.08 .

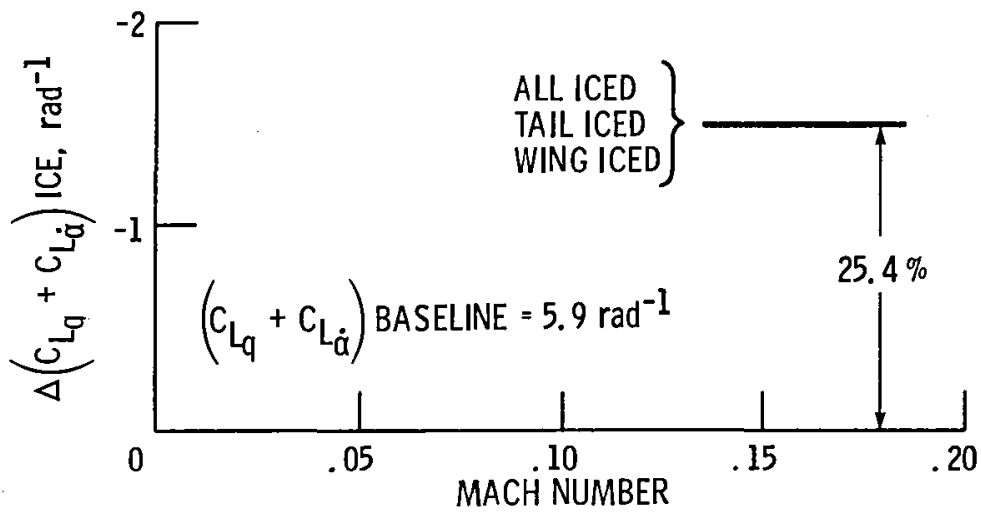

(b) Degradation in state coefficient at $\delta_{F}=10^{\circ}$ and $C_{T}=0.05$ to 0.07 .

Figure 33. - Effect of mixed icing conditions on the state coefficient for flights $86-16$ and $86-17$. Note, results were the same for both flights. 


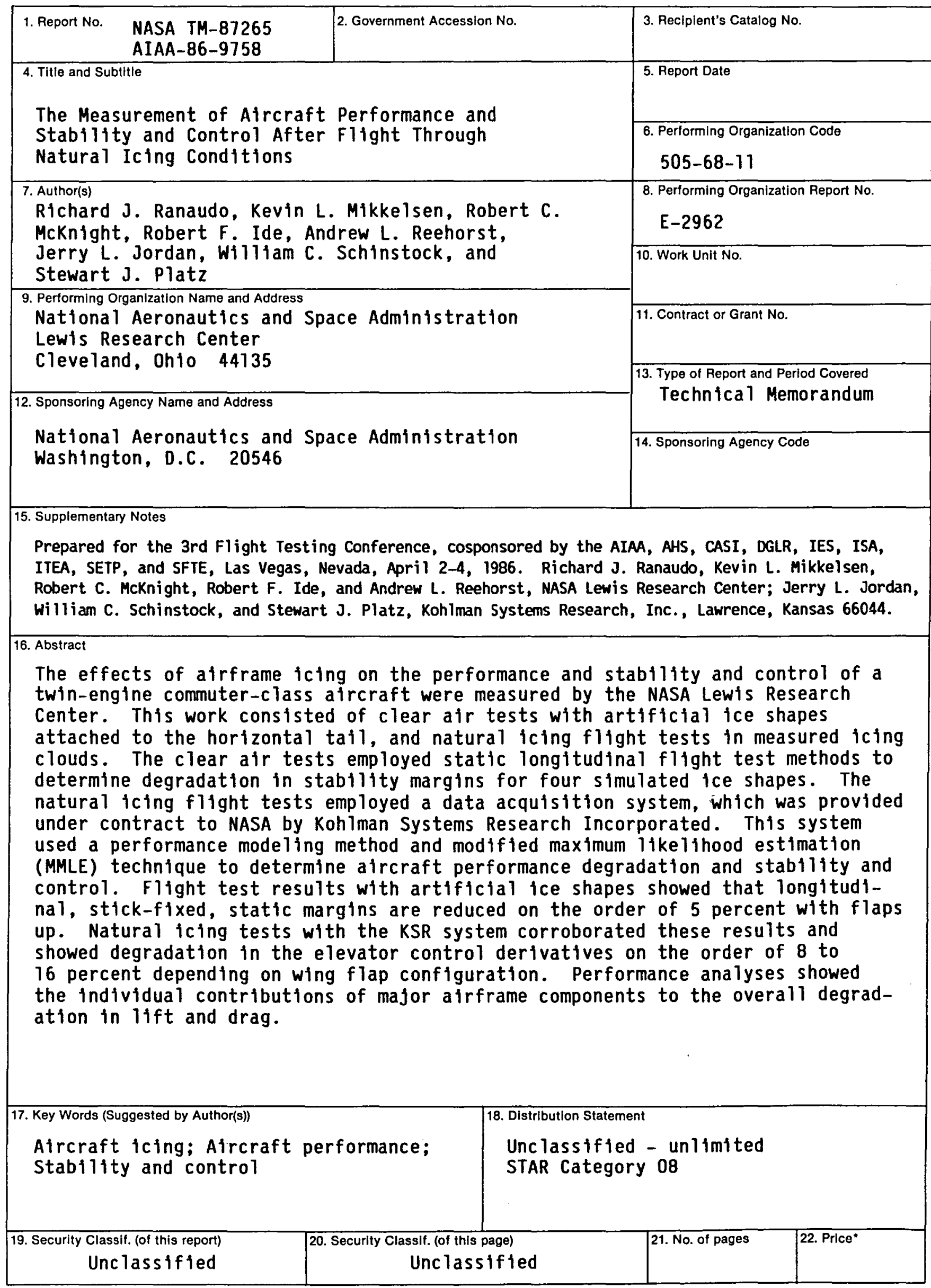

"For sale by the National Technical Information Service, Springfield, Virginia 22161 
End of Document 